\title{
MUDANÇAS CLIMÁTICAS, POLUIÇÃO DO AR E REPERCUSSÕES NA SAÚDE HUMANA: REVISÃO SISTEMÁTICA
}

\author{
FERNANDES, Thiago - thiago.ufra.pa@gmail.com \\ Universidade Federal Rural da Amazônia / UFRA \\ HACON, Sandra de Souza - sandrahacon@gmail.com \\ Fundação Oswaldo Cruz / FIOCRUZ
} NOVAIS, Jonathan Willian Zangeski - jonathan.novais@kroton.com.br
Universidade de Cuiabá / UNIC

Submetido em: $17 / 03 / 2020$

Aceito para publicação em: 14/01/2021

Publicado em: 06/04/2021

DOI: http://dx.doi.org/10.5380/abclima.v28i0.72297

\begin{abstract}
RESUMO: As principais implicações das mudanças climáticas e da poluição atmosférica sobre a saúde humana, tanto em nível global como no Brasil, têm sido objeto de atenção perante as instituições mundiais. Objetivo: Revisar a literatura sobre os efeitos das mudanças climáticas e da poluição do ar na saúde humana. Método: Revisão sistemática de pesquisas publicadas, entre os anos de 2010-2018, em bases de dados (PubMed, Dimensions, SciELO, Periódicos Capes) por meio de descritores-chaves alusivos à problemática de estudo. Foram selecionados 228 artigos, divididos e organizados sob duas dimensões de buscas e analisados pela técnica bibliométrica. Resultados: No geral, 54\% dos estudos foram publicados entre 2010-2012, em sua maioria, assinados por pesquisadores vinculados a instituições públicas brasileiras. A maior parte dos estudos foi realizada na Amazônia Legal e os grupos mais pesquisados foram crianças e idosos. O poluente atmosférico mais investigado foi o material particulado com diâmetro inferior a 2,5 $\mu \mathrm{m}$, que revelou ser um fator de risco grave à saúde humana. Encontrou-se também relação entre eventos climáticos extremos e o aumento do desmatamento e dos casos de morbimortalidade, sobretudo por doenças respiratórias. Conclusão: O fogo sobre a biomassa florestal oriunda do desmate é posto como uma das principais causas das mudanças climáticas e o MP 2,5 foi o poluente atmosférico que mais se associou aos agravos à saúde, principalmente nos grupos mais vulneráveis.
\end{abstract}

PALAVRAS-CHAVE: Mudanças climáticas; Poluição atmosférica; Desmatamento; Saúde pública; Bibliometria.

\section{CLIMATE CHANGE, AIR POLLUTION AND HUMAN HEALTH IMPACTS: SYSTEMATIC REVIEW}

ABSTRACT: The main implications of climate change and air pollution on human health, both globally and in Brazil, have been the subject of attention before world institutions. Objective: To review the literature on the effects of climate change and air pollution on human health. Method: Systematic review of research published, between 2010-2018, in databases (PubMed, Dimensions, SciELO, Periódicos Capes) by means of key descriptors alluding to the study problem. A total of 228 articles were selected, divided and organized under two search dimensions and analyzed by bibliometric technique. Results: Overall, 54\% of the studies were published between 2010-2012, mostly signed by researchers linked to Brazilian public institutions. Most of the studies were conducted in Legal Amazon and the most researched groups were children and elderly. The most investigated atmospheric pollutant was particulate material with a diameter of less than $2.5 \mu \mathrm{m}$, which revealed to be a serious risk factor to human health. There was also a relationship between extreme climatic events and increased deforestation and cases of morbidity and mortality, especially by respiratory diseases. Conclusion: The fire on forest biomass from deforestation is put as one of the main causes of climate change and the 
MP 2.5 was the atmospheric pollutant that was most associated with health hazards, especially in the most vulnerable groups.

KEYWORDS: Climate Change; Air Pollution; Deforestation; Public Health; Bibliometry.

CAMBIO CLIMÁTICO, CONTAMINACIÓN DEL AIRE E IMPACTOS EN LA SALUD HUMANA: UN EXAMEN SISTEMÁTICO

RESUMEN: Las principales consecuencias del cambio climático y la contaminación atmosférica para la salud humana, tanto a nivel mundial como en el Brasil, han sido objeto de atención por parte de las instituciones mundiales. Objetivo: Revisar la literatura sobre los efectos del cambio climático y la contaminación del aire en la salud humana. Método: Revisión sistemática de las investigaciones publicadas, entre 2010 y 2018, en bases de datos (PubMed, Dimensions, SciELO, Periódicos Capes) mediante descriptores clave alusivos al problema del estudio. Se seleccionaron un total de 228 artículos, divididos y organizados en dos dimensiones de búsqueda y analizados mediante la técnica bibliométrica. Resultados: En general, el 54\% de los estudios se publicaron entre 2010 y 2012, firmados en su mayoría por investigadores vinculados a instituciones públicas brasileñas. La mayoría de los estudios se realizaron en la Amazonia Legal y los grupos más investigados fueron los niños y los ancianos. El contaminante atmosférico más investigado fue el material particulado de menos de $2,5 \mu \mathrm{m}$ de diámetro, que reveló ser un grave factor de riesgo para la salud humana. También existía una relación entre los fenómenos climáticos extremos y el aumento de la deforestación y los casos de morbilidad y mortalidad, principalmente por enfermedades respiratorias. Conclusión: El incendio de la biomasa forestal debido a la deforestación se sitúa como una de las principales causas del cambio climático y el MP 2.5 fue el contaminante atmosférico que más se asoció a los riesgos para la salud, especialmente en los grupos más vulnerables.

PALABRAS CLAVE: Cambio climático; Contaminación del aire; Deforestación; Salud pública; Bibliometría.

\section{INTRODUÇÃO}

As mudanças climáticas não são uma questão nova para o setor de saúde. O primeiro informe científico sobre mudança climática e saúde foi publicado pela Organização Mundial de Saúde (OMS) em 1990. Hacon et al. (2010) citam que, em setembro de 1995, a Organização Panamericana de Saúde (OPAS) apresentou o tema para a Academia Nacional de Ciências dos Estados Unidos durante uma Conferência sobre as Mudanças Climáticas e Saúde Humana, ocorrida em Washington, nos Estados Unidos da América; desde então, uma série de estudos e evidências tem comprovado a questão e auxiliado as discussões no âmbito dos setores de ambiente e saúde, por meio de conferências internacionais (CARMO; GUIZARDI, 2018).

Segundo o $5^{\circ}$ Relatório de Avaliação do Painel Intergovernamental de Mudanças Climáticas (IPCC, em inglês), os riscos associados às mudanças climáticas globais devem ser considerados no contexto da globalização, das alterações ambientais, das políticas públicas e da governança (IPCC, 2015), com diferentes repercussões e intensidades locais. Fernandes et al. (2020) mencionam como exemplo as variações nos regimes de chuvas, tanto em quantidade quanto em intensidade, provocando diversos desastres naturais como enchentes e secas, mudanças no ambiente, como a alteração de ecossistemas e de ciclos biológicos, geográficos e químicos, que podem aumentar a incidência de doenças infecciosas e respiratórias, majoritariamente em países em desenvolvimento. No Brasil, o tema mudança climática está em ampla discussão, envolvendo progressivamente os setores governamentais, não governamentais e a comunidade em geral (FLEURY et al., 2019.) 
O tema foi incorporado como uma questão estratégica para o país, de forma a subsidiar e promover as discussões sobre seus efeitos em diversas áreas, dentre elas a saúde (DUARTE, 2019). Os desastres têm sido um grave e recorrente problema, acarretados por eventos como secas/estiagens, enchentes/inundações e, maiormente, incêndios/queimadas (NOBRE; MARENGO, 2017). Os incêndios florestais causados pelo uso do fogo em sistemas agrícolas afetam o equilíbrio dos ecossistemas, a saúde humana e, consequentemente, o planeta (GONÇALVES et al., 2012). A cada ano, o fogo na Amazônia brasileira atinge uma área equivalente a dez vezes o tamanho da Costa Rica (CARMO et al., 2010). Em 2020, por exemplo, o fogo aumentou nos meses que antecederam a estação seca. Somente junho de 2020 registrou quase $20 \%$ mais focos de calor em relação a junho de 2019 , enquanto julho de 2020 teve um aumento de $28 \%$ em relação a julho de 2019 (ALENCAR et al., 2020).

A queima de biomassa florestal, popularmente conhecida como "queimada", é uma prática recorrente e antiga no país e se caracteriza como um dos principais contribuintes mundiais para a emissão de Gases de Efeito Estufa GEE (SOUZA et al., 2017). Segundo dados do Sistema de Estimativa de Emissões de Gases de Efeito Estufa (SEEG) do Observatório do Clima (OCD), em 2018, o país emitiu 1,939 bilhão de toneladas brutas de GEE. Em termos de Dióxido de Carbono equivalente $\left(\mathrm{CO}_{2} \mathrm{e}\right)$, foi apenas $0,3 \%$ superior ao 1,932 bilhão de toneladas de Dióxido de Carbono em 2017. A contribuição de cada setor na emissão de GEE foi substancial; $44 \%$ vieram das mudanças de uso da terra, sobretudo do desmatamento na Amazônia e no Cerrado; seguido de $25 \%$ da agropecuária; $21 \%$ do setor de energia (que inclui todas as atividades que usam combustíveis fósseis) e, por fim, $5 \%$ dos processos industriais e de resíduos (ANGELO; RITTL, 2019). A variação das emissões se explica maiormente por uma alta na taxa de desmatamento na Amazônia, de 8,5\% em 2018, que elevou as emissões daquele bioma em 44,5 milhões de toneladas, mas foi parcialmente compensada por uma redução de $9,25 \%$ nas emissões no Cerrado. No total, as emissões por mudança de uso da terra subiram 3,6\% (ODC, 2019).

Para Gonçalves et al. (2012), este desequilíbrio no ambiente é influenciado pelo acelerado crescimento populacional, pelas variações no padrão de consumo e pela intensificação das atividades de força econômica, capazes de exercer pressões sobre o nível de qualidade de vida das populações expostas. Essas alterações no uso e na ocupação do solo são responsáveis por emissões expressivas de partículas de aerossóis para a atmosfera por meio das queimadas, tanto de áreas de pastagem quanto de floresta, afetando grupos sociais mais vulneráveis, como crianças e idosos (BARCELLOS et al., 2009).

Estudos epidemiológicos têm demonstrado que, em relação à exposição aos poluentes da atmosfera em diferentes partes do mundo, a taxa de mortalidade por internações e doenças respiratórias e cardiovasculares continua aumentando (ANDRADE-FILHO et al., 2013). Isso ocorre principalmente nas populações mais suscetíveis como crianças, idosos e pessoas com histórico de doença cardiopulmonar (faixas etárias de maior vulnerabilidade à exposição), mesmo que as regulamentações ambientais considerem o nível de exposição seguro (ROSA et al., 2008; ANDRADE-FILHO et al., 2013; CORRÊA et al., 2020). 
As crianças, por sua vez, fazem parte desse subgrupo, pois o contato direto do material particulado com o seu sistema respiratório pode causar sintomas graves em pouco tempo (MORAES et al., 2019). Crianças apresentam o volume respiratório minuto/peso corporal maior do que adultos, o que contribui para exposição maior aos poluentes atmosféricos (LEÃO et al., 2018). Além disso, os sistemas imunológico e respiratório das crianças ainda estão se desenvolvendo e elas passam mais tempo ao ar livre do que os adultos, aumentando sua exposição a vapores tóxicos; portanto, elas são mais suscetíveis a partículas lançadas na atmosfera (MENEZES et al., 2019; BUENO et al., 2020).

Para aqueles com problemas cardíacos ou respiratórios (como os idosos), as partículas finas e ultrafinas encontradas na fumaça podem agravar doenças crônicas do coração e dos pulmões e estão associadas à morte prematura desse grupo (MEIMEI et al., 2014; DASTOORPOOR et al., 2019; YAP et al., 2019). A suscetibilidade dos idosos às infecções respiratórias e suas complicações é um importante motivo de hospitalização e morte em alguns países do mundo (RÉQUIA; ABREU, 2011). Esse fato pode ser explicado em parte pelo declínio gradual da função pulmonar em idosos, que depende da elasticidade pulmonar, da perda da capacidade vital e do volume expiratório forçado, além da diminuição da função ciliar e do reflexo da tosse enfraquecido (ARBEX et al., 2012; TORRES et al., 2020). Por isso, essa suscetibilidade, associada à poluição atmosférica, pode ocasionar o aumento de atendimentos por diversas doenças respiratórias em idosos (CORRÊA et al., 2020). Outros fatores associados são a baixa imunidade e a redução da função do trato respiratório superior, que contribuem para aumentar a indefensabilidade e para o adoecimento respiratório relacionado aos poluentes do ar (IGNOTTI et al., 2010). Logo, este estudo tem por objetivo apresentar uma revisão sistemática à luz da literatura científica contemporânea mundial sobre os efeitos das mudanças climáticas e da poluição do ar na saúde humana.

\section{METODOLOGIA}

\section{DESENHO DO ESTUDO}

Trata-se de estudo de revisão sistemática (estado da arte) em diferentes bases de dados eletrônicas científicas, por intermédio de descritores-chaves, em artigos publicados que abordaram, por meio de pesquisas epidemiológicas com delineamento do tipo ecológico, a temática da associação entre mudanças climáticas e poluição do ar e seus desfechos na saúde humana.

\section{BASES DE DADOS ELETRÔNICAS E ESTRATÉGIA DE BUSCA}

O levantamento dos estudos consistiu em uma busca direcionada em bases de dados de referência na temática, escolhidas e agrupadas em duas dimensões: (i) internacional e (ii) nacional, seguindo os mesmos procedimentos didáticos e éticos feitos por Souza et al. (2017). Essa divisão por dimensões possibilita identificar o alcance da temática de estudo, dos grupos sociais e de pesquisadores com expertise na área. À vista disso, foram estabelecidas as seguintes bases de dados, conforme mostra a Tabela 1. 
Tabela 1 - Dimensões de buscas e bases de dados utilizadas para conduzir a revisão sistemática do estudo.

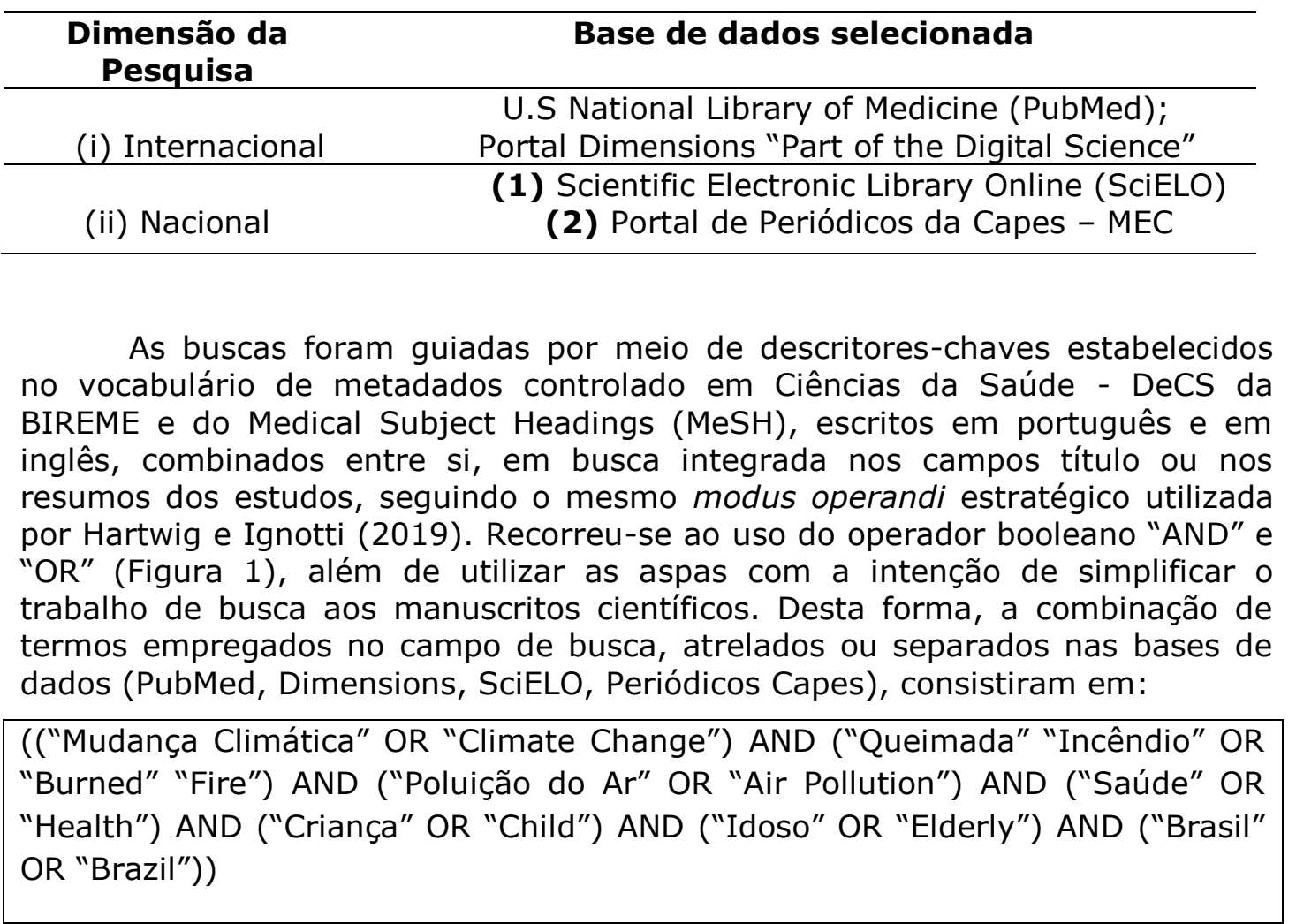

Figura 1 - Descritores usados como estratégia de busca.

\section{SELEÇÃo E ANÁLISE dAS PUBLICAÇÕES}

Na fase de busca, não houve restrição em relação ao idioma dos artigos. Contudo, após essa etapa, foram incluídos na revisão sistemática apenas trabalhos em português ou inglês, publicados entre janeiro de 2010 até dezembro de 2018. Para seleção dos artigos, foi estabelecido como instrumento de coleta o uso de um formulário específico, com as seguintes informações: autor(es); cidade/estado onde desenvolveu a pesquisa; ano de publicação e título do artigo. Em seguida, foram renomeados com uso da linguagem de números ordinais.

Foram abrangidos nesta revisão somente artigos originais, publicados em periódicos internacionais ou nacionais, desde que estivessem indexados em uma das bases de dados antes referidas e que tivessem clareza quanto aos critérios de inclusão: (i) informações sobre os grupos sociais pesquisados (crianças e idosos); (ii) dados sobre tipos de poluentes atmosféricos (Material particulado com diâmetro 2,5 $\mu \mathrm{m}$ e $10 \mu \mathrm{m}$; (iii) tipo de estudo e Instrumento de Coleta de Dados utilizado (ICD); e (iv) efeitos sobre a saúde humana. Não houve restrição com relação ao sexo e nem ao tempo de exposição, embora tenha-se dado preferência à inclusão de artigos com foco de pesquisa para crianças menores de 5 anos de idade e adultos acima de 65 anos de idade. Foram excluídos 
artigos de metanálises, editoriais, relatos de casos e artigos que tratavam de abordagens estritamente clínicas e experimentais. Desta forma, o modelo conceitual do tipo de pesquisa resume-se no mapofluxograma (Figura 2).

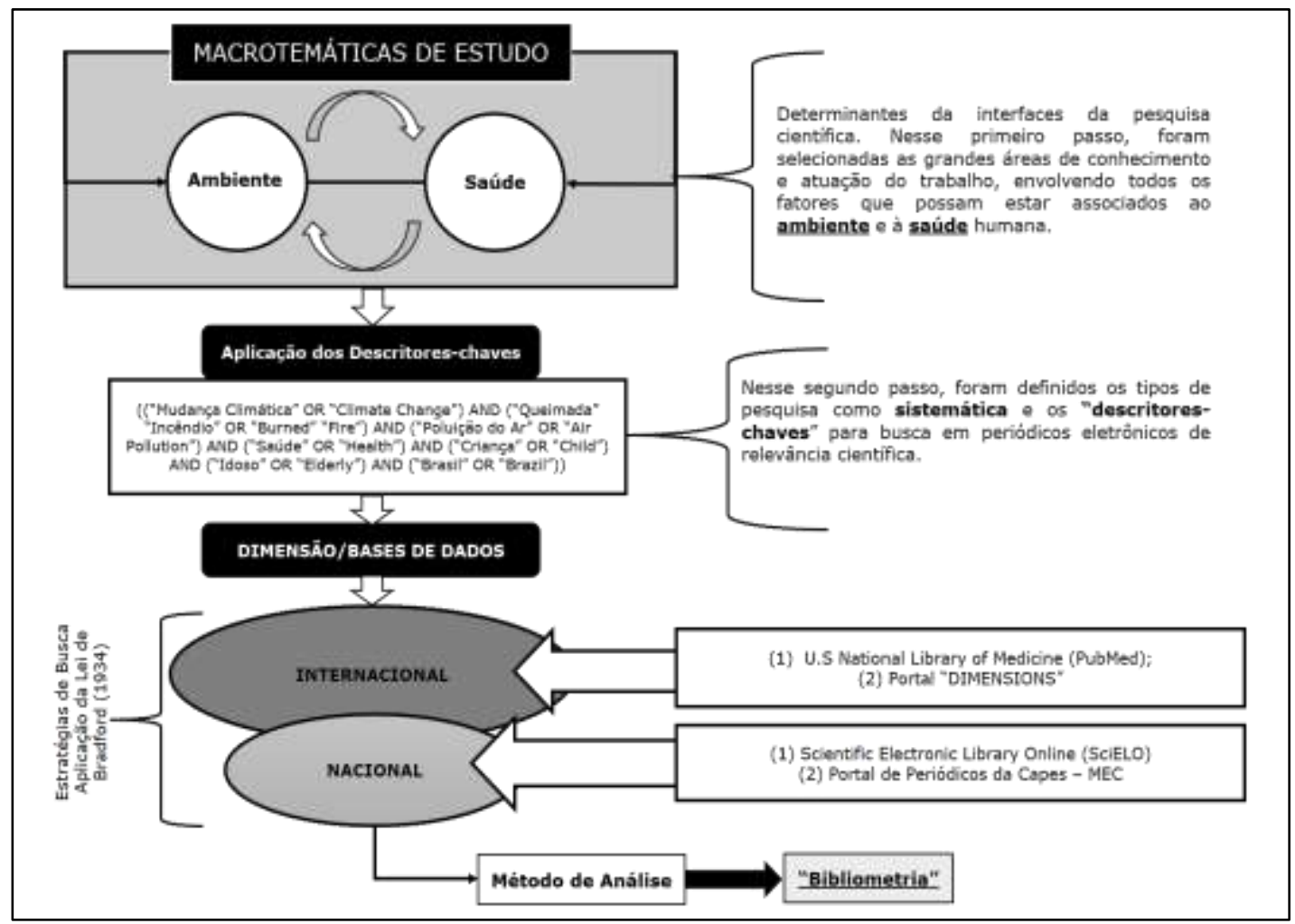

Figura 2 - Mapofluxograma conceitual do tipo de pesquisa, suas abordagens dimensionais, descritores-chaves e forma de análise.

A métrica de análise aplicada foi a bibliometria, que, para Araújo (2006), consiste no estudo dos aspectos quantitativos da produção intelectual, na disseminação de seu conteúdo e no uso da informação registrada por seus pares. Como indicador de dimensionamento do alcance literário, utilizou-se a Lei de Dispersão do Conhecimento Científico de Bradford (1934), que, segundo Alcântara e Sampaio (2017), é uma técnica cujo desígnio é descobrir quantos manuscritos de um assunto científico específico aparecem em periódicos. A presente pesquisa blinda-se de importância pelo fato de analisar dados e informações sobre a produção científica que aborda a temática em questão e sua relevância social para a ciência.

No geral, foram extraídos das bases de dados 277 (duzentos e setenta e sete) manuscritos científicos. Após análise minuciosa de todo o conjunto de dados, foram identificados 228 (duzentos e vinte e oito) artigos associando os efeitos das mudanças climáticas e da poluição do ar na saúde humana. Entre os estudos identificados, 178 (cento e setenta e oito), ou seja, 64\% foram descobertos nas bases de dados da dimensão internacional e 50 (cinquenta) nas bases de dados da dimensão nacional, correspondendo, assim, a 36\%. Desta 
forma, devido ao volume exacerbado de manuscritos encontrados nas bases de dados da dimensão internacional citadas, optou-se por enquadrar seus resultados neste estudo de forma quantitativa e ilustrativa, usando, assim, o software VOSviewer 1,6, que compactou as informações, gerindo, ao final do processo, uma rede interdisciplinar das interações entre os autores ao longo do tempo.

Os trabalhos descobertos nas bases de dados da dimensão nacional citadas foram selecionados para integrar a presente revisão sistemática de literatura. Os resultados obtidos com a aplicação da estratégia de busca estão expostos nos fluxogramas representativos do estudo em formato de figuras.

\section{RESULTADOS E DISCUSSÃO \\ DIMENSÃO DOS ESTUDOS INTERNACIONAIS}

Na dimensão internacional, foram identificados nas bases de dados 204 artigos diretamente relacionados com a temática do estudo. Desse quantitativo preliminar, 17 artigos foram retirados por apresentar duplicidades entre si, tanto no título como no resumo. Por conseguinte, após uma leitura minudenciada do escopo textual, 09 artigos foram excluídos por se tratarem de estudos clínicos e experimentais, e foram incluídos 178 artigos ao final desse processo decisório. Esse procedimento de seleção e elegibilidade está representado na Figura 3.

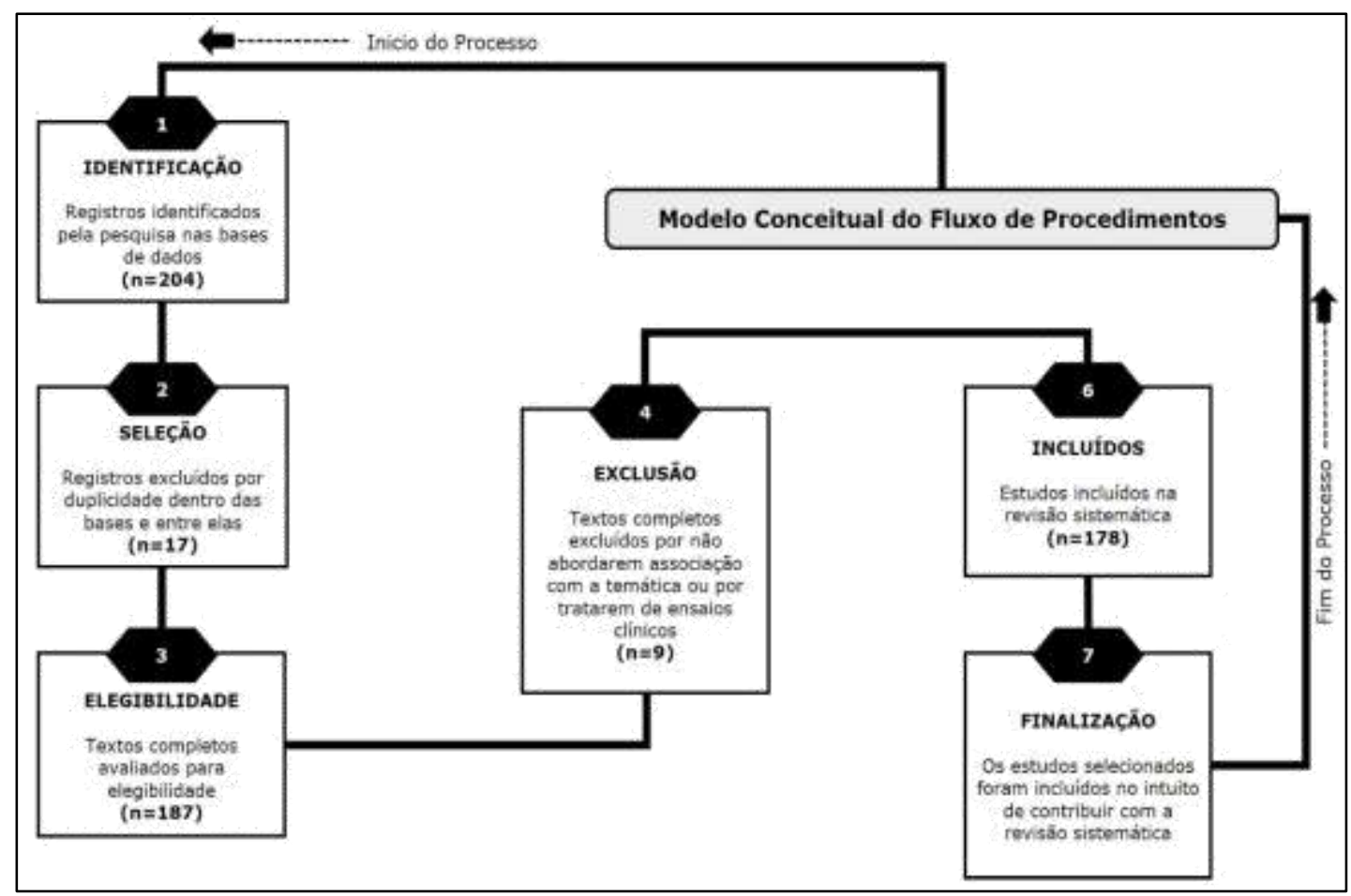

Figura 3 - Fluxograma do processo de identificação, seleção, elegibilidade e inclusão dos artigos na revisão sistemática (dimensão internacional).

Foram selecionados 178 artigos, dos quais 112 são de língua portuguesa e 66 de língua inglesa. Os anos de maior publicação foram 2010, com 21,35\%; 
2011, com 17,98\% das publicações; e 2012, com 14,61\% (Tabela 2). Observase que os estudos que envolvem a temática abordada, principalmente a relação entre saúde e poluição do ar, são pesquisados muito antes de 2010 (IGNOTTI et al., 2010); além disso, esta temática é uma preocupação técnico-científica para a saúde humana que está presente na sociedade há muitas décadas (desde o século $X X$ ) no Brasil e no mundo (RIGOTTO; AUGUSTO, 2007). Nota-se na Tabela 2 um aumento de publicações depois do ano de 2010. Essa observação pode ser devida à notificação feita pelas agências de monitoramento quanto ao acréscimo de queimadas e incêndios florestais na região Norte e Centro-Oeste do Brasil, entre o período de 2010 - 2015 (FONSECA-MORELLO et al., 2017), acrescendo a emissão de particulados no ar, o que pode ter corroborado com os agravos na saúde dos grupos mais vulneráveis (crianças e idosos) (FERNANDES et al., 2019). Outros achados científicos também mostram que houve aumento de estudos epidemiológicos em países em desenvolvimento (VENTURA et al., 2020).

Tabela 2 - Descrição e ordenamento dos anos de publicação dos artigos.

\begin{tabular}{ccc}
\hline Anos de Publicação & No de Artigos Publicados & $\mathbf{( \% )}$ \\
\hline 2010 & 38 & 21,35 \\
2011 & 32 & 17,98 \\
2012 & 26 & 14,61 \\
2013 & 21 & 11,80 \\
2014 & 19 & 10,67 \\
2015 & 16 & 8,99 \\
2016 & 12 & 6,74 \\
2017 & 09 & 5,06 \\
2018 & 05 & 2,80 \\
\hline Total & $\mathbf{1 7 8}$ & $\mathbf{1 0 0}$ \\
\hline
\end{tabular}

Por meio da compactação dos dados e das informações encontrados nas bases científicas na dimensão internacional, foi possível identificar os principais pesquisadores com expertise na área, que contribuíram com a produção científica referente à temática, e tão logo delineou-se uma "rede de interações" entre eles, conforme mostra a Figura 4. 


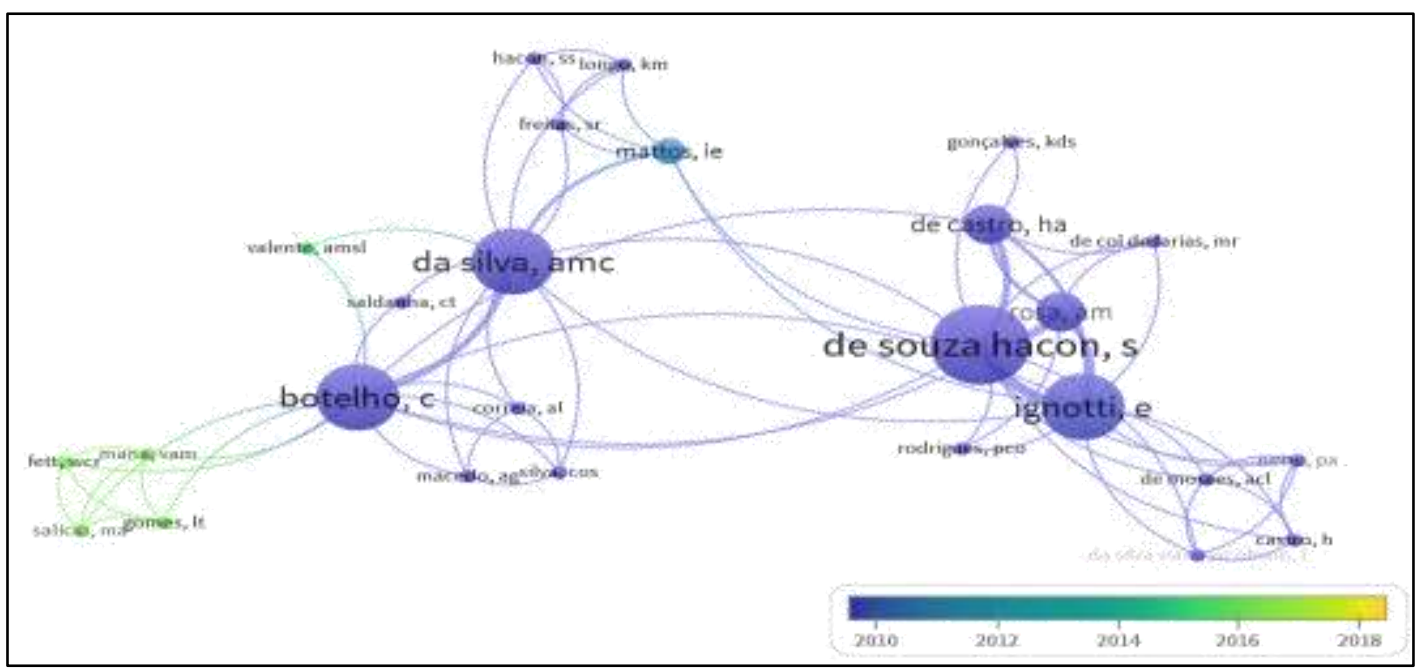

Figura 4 - Rede de interações interdisciplinares entre os principais pesquisadores com expertise na temática de estudo.

Salienta-se que a maioria dos artigos científicos aparece publicados entre os anos de 2010-2012, avaliados nesse contexto como a maior série de divulgação de resultados de pesquisas em saúde e ambiente, coincidindo com os muitos problemas ambientais que "assustaram" a comunidade científica, por exemplo, aumento do desmatamento na Amazônia Legal, focos de queimadas em grandes proporções no Sul da Amazônia, queima da palhada da cana-deaçúcar na região médio norte do estado de Mato Grosso, criando, atualmente, uma fronteira agrícola para o agronegócio (FERNANDES et al., 2019).

$\mathrm{Na}$ "rede de interações" entre pesquisadores, observam-se pressupostos teóricos como Hacon, Ignotti, Botelho, Da Silva, Rosa e De Castro como os que exibiram maior produtividade científica relacionada com a temática, destacandose na rede por exporem 3 (três) ou mais manuscritos publicados com autoria ou coautoria durante a série de estudo. Destarte, pela análise bibliométrica, os autores citados também se destacaram por exibirem a frequência sazonal de 5 (cinco) ou mais citações de seus manuscritos, conforme mostra a Tabela 3.

Tabela 3 - Descrição da frequência sazonal de citações e publicações dos principais autores nas bases de dados referente à dimensão internacional.

\begin{tabular}{ccc}
\hline $\begin{array}{c}\text { Principais Autores } \\
\text { Frequência de } \\
\text { Citações }\end{array}$ & $\begin{array}{c}\text { No Total de Publicações } \\
\text { (Autoria e Coautoria) }\end{array}$ \\
\hline Hacon et al. & 6 & 13 \\
Ignotti et al. & 5 & 12 \\
Rosa et al. & 3 & 09 \\
De Castro et al. & 3 & 08 \\
Botelho et al. & 5 & 07 \\
\hline
\end{tabular}

Para a Organização Mundial de Saúde (OMS), estudos com base na temática de mudanças climáticas e poluição do ar e seus efeitos na saúde 
humana são de preocupação mundial, sobretudo quando o modelo de desenvolvimento de um país acaba interferindo no bem viver da população de outros, distanciando cada vez mais do que se entende por melhor qualidade de vida (OMS, 2008). Logo, observou-se uma conexão na produção e divulgação científica entre pesquisadores de diversos países, por exemplo, Estados Unidos, Brasil, Inglaterra, Suíça, África do Sul, Rússia, França, entre outros, que, de forma alusiva, compartilharam resultados expressivos por meio de uma espécie de rede intercontinental promovida pelas instituições e organizações internacionais (ECHEGARAY; AFONSO, 2014).

\section{DIMENSÃO DOS ESTUDOS NACIONAIS}

Por meio dos resultados obtidos nas bases de dados da dimensão nacional, foram identificados 73 artigos que atenderam, em um primeiro momento, à demanda da pesquisa. Entretanto, a partir de uma leitura mais aprofundada no escopo textual, 17 artigos foram excluídos por apresentarem duplicidade na base de dados. Em seguida, na fase de elegibilidade, 6 artigos foram descartados por não abordarem a temática e por se tratarem de manuscritos de ensaios clínicos com seres humanos. Essas fases sistêmicas estão evidenciadas na Figura 5.

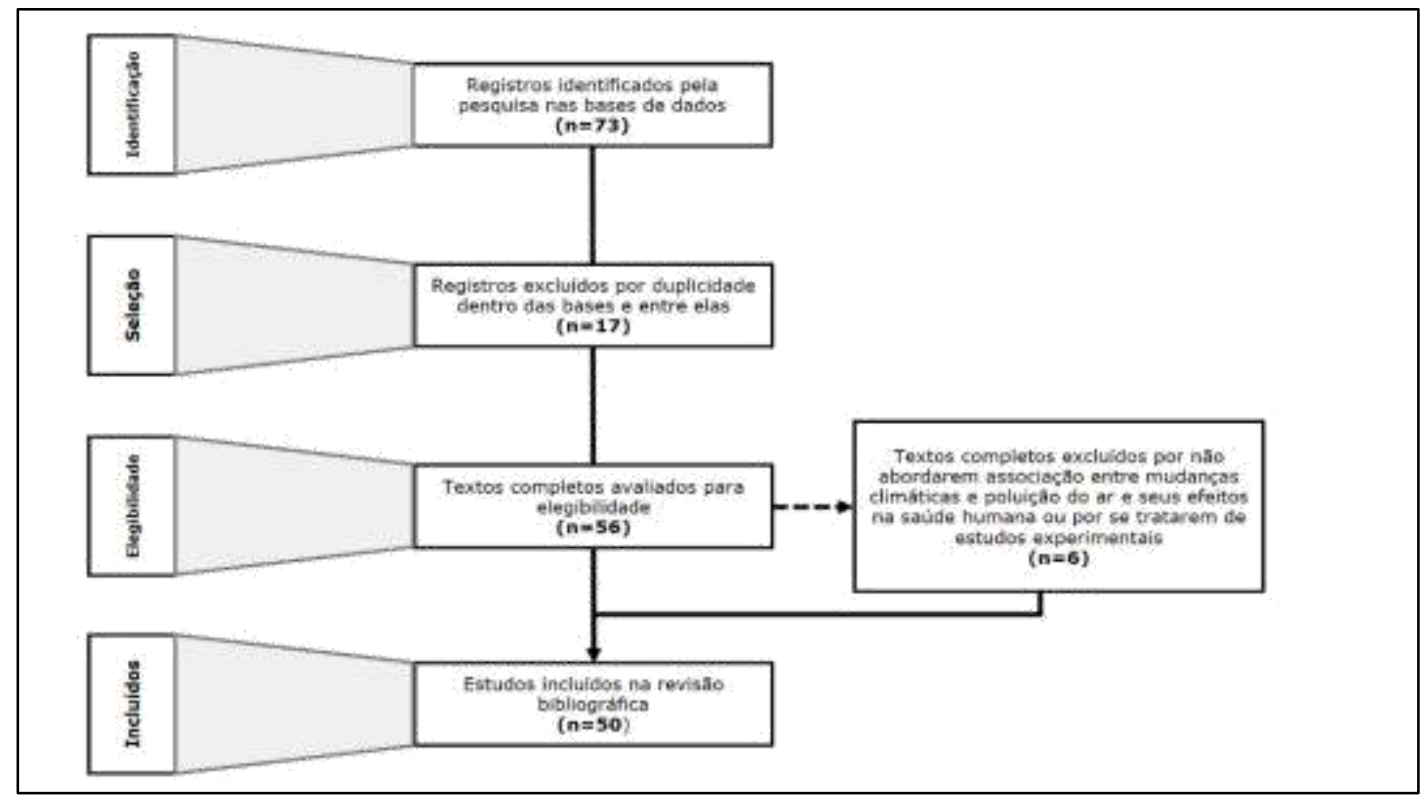

Figura 5 - Modelo conceitual do fluxo representativo do processo de identificação, seleção, elegibilidade e inclusão dos artigos na revisão de literatura.

Foram enquadrados 50 artigos, dos quais 39 são de língua portuguesa e 11 de língua inglesa. Esses, por sua vez, foram traduzidos e incorporados na revisão da literatura, com nominação ordinal e título em português. Os anos de maior publicação foram 2014, com 20\%; 2013, com 18\%, e 2010, 2012, 2016 e 2017 com 12\% (Tabela 4), o que demonstra que o interesse pela temática é crítico-preocupante para a comunidade científica brasileira. 
Tabela 4: Descrição e ordenamento dos anos de publicação dos artigos.

\begin{tabular}{ccc}
\hline Anos de Publicação & No de Artigos Publicados & (\%) \\
\hline 2010 & 06 & 12 \\
2011 & 02 & 4 \\
2012 & 06 & 12 \\
2013 & 09 & 18 \\
2014 & 10 & 20 \\
2015 & 03 & 6 \\
2016 & 06 & 12 \\
2017 & 06 & 12 \\
2018 & 02 & 4 \\
\hline Total & $\mathbf{5 0}$ & $\mathbf{1 0 0}$ \\
\hline
\end{tabular}

Após a primeira categorização temática, foi priorizada uma releitura completa do corpo textual dos artigos e tão logo foi providenciada uma nova readequação por similitude de conteúdo. Noutro momento, foi possível relacionar os agentes causadores $\left(\mathrm{MP}_{2,5}, \mathrm{MP}_{10}\right.$, queimadas, mudanças climáticas e outros) com os desfechos em saúde, além de grupos sociais vulneráveis, possibilitando esquematizar uma teia interdisciplinar dos artigos científicos (Figura 6).

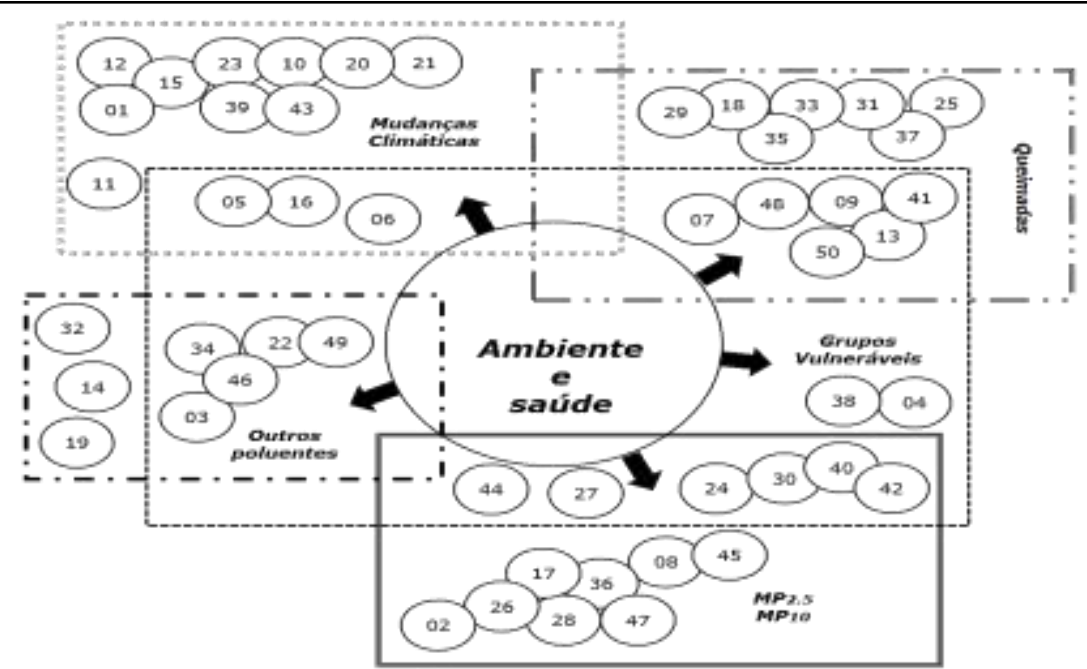

Figura 6 - Teia interdisciplinar com as interações dos artigos identificados extraídos das bases de dados nacionais e incluídos na revisão deste estudo.

Para Ruiz et al. (2009), é indiscutível o papel das revistas científicas para comunicar e tornar públicos o debate e o avanço da ciência, com a ruptura de antigos paradigmas e o estabelecimento de novos, em um ciclo de renovação, que é uma das bases do processo científico. 
As indexações periódicas também são importantes nesse cenário, por se tratarem da escolha do meio de comunicação do pesquisador para disseminar a ciência e os conhecimentos produzidos. Para uma revista, a indexação nas bases de dados significa reconhecimento do mérito científico, aval à qualidade de seus artigos e, consequentemente, para seus autores. Por isso, na dimensão nacional, os principais periódicos científicos escolhidos pelos autores e coautores para publicação foram identificados e estão representados na Figura 7.

Foram levantados apenas os periódicos científicos de maior circulação nacional, e muitos desses, tradicionalmente, estão entre os que exibiram, em 2017, o Journal Citation Reports (JCR) igual ou superior a 0,900 e, atualmente, com número de citações acima de 1 (um) mil, segundo relatório produzido pela InCites Journal Citation Reports - Clarivate Analytics. Dos 50 (cinquenta) artigos presentes na revisão sistemática, observou-se a temática identificada em 13 (treze) artigos inclusos na área de Saúde Coletiva, correspondendo a $26 \%$; 9 (nove) artigos na área de Ciências Ambientais (18\%); 8 (oito) artigos na área Interdisciplinar (16\%); 8 (oito) artigos na área de Enfermagem (16\%); 6 (seis) artigos na área de Medicina I (12\%); 3 (três) artigos na área de Geociência (6\%); e, por fim, 3 (três) em Planejamento Urbano e Regional (6\%).

\begin{tabular}{|c|c|c|c|c|c|}
\hline ISSN & Título do Periódico & Área de Avaliaçăo & Classificaçăo* & No de Publicações & $\%$ \\
\hline & & Clências Ambientais & A2 & 2 & 4 \\
\hline \multirow{4}{*}{$0102-311 x$} & Cadernos de Saúde & Enfermagem & B1 & 3 & 6 \\
\hline & Pública & Interdisciplinar & $\mathrm{A} 2$ & 1 & 2 \\
\hline & & Medidna I & 82 & 3 & 6 \\
\hline & & Saúde Coletiva & $A 2$ & 4 & 8 \\
\hline & & Ciencias Ambientais & A2 & 1 & 2 \\
\hline \multirow[t]{4}{*}{ 0034-8910 } & Revista de Saúde Pública & Enfermagem & A2 & 1 & 2 \\
\hline & & Interdisciplinar & B1 & 0 & $=$ \\
\hline & & Planej. Urbano e Regional & A1 & 3 & 6 \\
\hline & & Crências Ambientais & B1 & 2 & 4 \\
\hline \multirow[t]{4}{*}{$1990-5497$} & Revista Brasileira de & Enfermagem & B1 & 2 & 4 \\
\hline & Epiderniologia & Geociêndas & $\mathrm{B} 2$ & 2 & 4 \\
\hline & & Interdisciplinar & B1 & 3 & 6 \\
\hline & & Saúde Coletiva & B1 & 2 & 4 \\
\hline \multirow{4}{*}{$1982-3258$} & & Enfermagem & 81 & 1 & 2 \\
\hline & Revista Glência e Saúde & Geociências & B2 & 1 & 2 \\
\hline & Coletiva & Interdisciplinar & B1 & 1 & 2 \\
\hline & & Saúde Coletiva & B1 & 3 & 6 \\
\hline \multirow{5}{*}{$1806-3713$} & & Cléncias Ambientais & 82 & 0 & - \\
\hline & Jornal Brasileiro de & Enfermagem & B1 & 1 & 2 \\
\hline & Pneumologia & Interdisciplinar & B1 & 1 & 2 \\
\hline & & Medidna I & 82 & 3 & 6 \\
\hline & & Saúde Coletiva & $\mathrm{B2}$ & 4 & 8 \\
\hline \multirow{4}{*}{$2237-8642$} & & Côncias Ambientais & A2 & 3 & 6 \\
\hline & Revista Brasileira de & & & & \\
\hline & Climatologia & Interdisciplinar & B2 & 0 & - \\
\hline & & Geografia & B1 & 0 & - \\
\hline \multirow[t]{3}{*}{$2179-7536$} & Revista Novos Cademos & Cências Ambientais & B1 & 1 & 2 \\
\hline & NAEA & Interdisciplinar & B2 & 2 & 4 \\
\hline & & & & 50 & 100 \\
\hline
\end{tabular}

Figura 7 - Códigos, Revistas, Áreas-eventos de publicação na dimensão de análise nacional. *Classificação - Quadriênios 2013-2016 (Sucupira Capes).

Noutro momento, a Tabela 5 exibe a econometria das informações distribuída por regiões brasileiras, que mensurou os principais estudos ecológicos e epidemiológicos associados aos efeitos das mudanças climáticas e 
da poluição do ar na saúde humana, com resultados delineados no território brasileiro. Foram identificados 18 (dezoito) artigos para a região Norte, correspondendo a 36\%; 3 (três) artigos para a região Sul (6\%); 12 (doze) artigos para a região Centro-Oeste $(24 \%) ; 2$ (dois) artigos para a região Nordeste (4\%); e, por último, 15 (quinze) artigos para a região Sudeste $(30 \%)$.

Tabela 5 - Levantamento econométrico das publicações sobre os principais estudos ecológicos e epidemiológicos por regiões brasileiras entre 2010 - 2018.

\begin{tabular}{ccc}
\hline Regiões Brasileiras & No Publicações & \% \\
\hline Norte & 18 & 36 \\
Sul & 3 & 6 \\
Centro-Oeste & 12 & 24 \\
Nordeste & 2 & 4 \\
Sudeste & 15 & 30 \\
\hline Total & $\mathbf{5 0}$ & $\mathbf{1 0 0}$
\end{tabular}

A fim de estabelecer transparência nos resultados, são exibidos na Figura 8, de forma crescente, os estudos incluídos nessa revisão sistemática, esboçados pela dimensão nacional e que abordaram a temática. Nessa relação, as pesquisas citadas foram tidas na prerrogativa como os principais estudos de desenvolvimento com grupos de riscos (populações mais suscetíveis e vulneráveis) às mudanças climáticas e poluição do ar, no Brasil, entre 20102018.

\begin{tabular}{|c|c|c|c|}
\hline Autor(es) & Cidade(s) & Ano & Título de Estudo \\
\hline $\begin{array}{l}\text { Ribeiro } \\
\text { Pesquero }\end{array}$ & $\begin{array}{l}\text { Espírito Santo } \\
\text { do Turvo } \\
\text { (SP) }\end{array}$ & 2010 & $\begin{array}{l}\text { Queimadas de cana-de-açúcar: avaliação } \\
\text { de efeitos na qualidade do ar e na saúde } \\
\text { respiratória de crianças }\end{array}$ \\
\hline Ignotti et al. & $\begin{array}{l}\text { Tangará da } \\
\text { Serra e Alta } \\
\text { Floresta } \\
\text { (MT) }\end{array}$ & 2010 & $\begin{array}{l}\text { Poluição do ar e admissões hospitalares } \\
\text { por doenças respiratórias na Amazônia } \\
\text { subequatorial }\end{array}$ \\
\hline Hacon et al. & Brasil & 2010 & $\begin{array}{l}\text { Vulnerabilidade, riscos e impactos das } \\
\text { mudanças climáticas sobre a saúde do } \\
\text { Brasil }\end{array}$ \\
\hline $\begin{array}{l}\text { Rodrigues } \\
\text { et al. }\end{array}$ & $\begin{array}{l}\text { Estados da } \\
\text { Região Norte }\end{array}$ & 2010 & $\begin{array}{l}\text { Distribuição espacial das internações por } \\
\text { asma em idosos na Amazônia brasileira }\end{array}$ \\
\hline Farias et al. & $\begin{array}{ll}\text { Municípios } & \text { do } \\
\text { Sudoeste } & \text { da } \\
\text { Amazônia } & \\
\end{array}$ & 2010 & $\begin{array}{l}\text { Prevalência de asma em escolares de Alta } \\
\text { Floresta - município ao sudoeste da } \\
\text { Amazônia brasileira }\end{array}$ \\
\hline Carmo et al. & $\begin{array}{l}\text { Alta Floresta } \\
\text { (MT) }\end{array}$ & 2010 & $\begin{array}{l}\text { Associação entre material particulado de } \\
\text { queimadas e doenças respiratórias na } \\
\text { região sul da Amazônia brasileira }\end{array}$ \\
\hline Jasinski et al. & $\begin{array}{l}\text { Cubatão } \\
(\mathrm{SP})\end{array}$ & 2011 & $\begin{array}{l}\text { Poluição atmosférica e internações } \\
\text { hospitalares por doenças respiratórias em } \\
\text { crianças e adolescentes em Cubatão, São } \\
\text { Paulo, Brasil, entre } 1997 \text { e } 2004\end{array}$ \\
\hline Pereira et al. & $\begin{array}{l}\text { Alta Floresta } \\
\text { (MT) }\end{array}$ & 2011 & $\begin{array}{l}\text { Análise dos atendimentos ambulatoriais } \\
\text { por doenças respiratórias no Município de } \\
\text { Alta Floresta - Amazônia brasileira }\end{array}$ \\
\hline
\end{tabular}




\begin{tabular}{|c|c|c|c|}
\hline $\begin{array}{l}\text { Amâncio } \\
\text { Nascimento }\end{array}$ & $\begin{array}{l}\text { São José dos } \\
\text { Campos (SP) }\end{array}$ & 2012 & $\begin{array}{l}\text { Asma e poluentes ambientais: um estudo } \\
\text { de séries temporais }\end{array}$ \\
\hline $\begin{array}{l}\text { Carneseca } \\
\text { et al. }\end{array}$ & $\begin{array}{l}\text { Ribeirão } \\
\text { Preto } \\
\text { (SP) }\end{array}$ & 2012 & $\begin{array}{l}\text { Associação entre a poluição atmosférica } \\
\text { por material particulado e contagens } \\
\text { mensais de procedimentos de inalação e } \\
\text { nebulização em Ribeirão Preto-SP }\end{array}$ \\
\hline Nascimento & $\begin{array}{l}\text { São José dos } \\
\text { Campos (SP) }\end{array}$ & 2012 & $\begin{array}{l}\text { Poluentes ambientais e internações } \\
\text { devido a acidente vasculoencefálico }\end{array}$ \\
\hline Yanagi et al. & $\begin{array}{l}\text { São Paulo } \\
\text { (SP) }\end{array}$ & 2012 & $\begin{array}{l}\text { Influência do material particulado } \\
\text { atmosférico na incidência e mortalidade } \\
\text { por câncer no município de SP, Brasil }\end{array}$ \\
\hline Oliveira et al. & $\begin{array}{l}\text { Tangará } \\
\text { Serra } \\
\text { (MT) }\end{array}$ & 2012 & 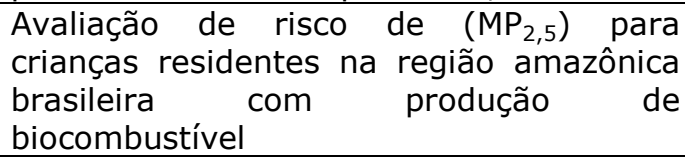 \\
\hline $\begin{array}{l}\text { Goncalves } \\
\text { et al. }\end{array}$ & $\begin{array}{l}\text { Amazônia } \\
\text { brasileira }\end{array}$ & 2012 & $\begin{array}{l}\text { As queimadas na região Amazônica e o } \\
\text { adoecimento respiratório }\end{array}$ \\
\hline Cesar et al. & $\begin{array}{l}\text { Piracicaba } \\
\text { (SP) }\end{array}$ & 2013 & $\begin{array}{l}\text { Associação entre exposição ao material } \\
\text { particulado e internações por doenças } \\
\text { respiratórias em crianças }\end{array}$ \\
\hline $\begin{array}{l}\text { Andra } \\
\text { al. }\end{array}$ & $\begin{array}{l}\text { Manaus } \\
(\mathrm{AM})\end{array}$ & 2013 & $\begin{array}{l}\text { Aerossóis de queimadas e doenças } \\
\text { respiratórias em crianças, Manaus }\end{array}$ \\
\hline Barros et al. & $\begin{array}{l}\text { Porto Velho } \\
\text { (RO) }\end{array}$ & 2013 & $\begin{array}{l}\text { Reinternações hospitalares por doenças } \\
\text { respiratórias em menores de } 12 \text { anos e as } \\
\text { queimadas em Porto Velho-RO }\end{array}$ \\
\hline Nunes et al. & $\begin{array}{l}\text { Micro áreas da } \\
\text { Amazônia } \\
\text { brasileira }\end{array}$ & 2013 & $\begin{array}{l}\text { Mortalidade por doenças circulatórias na } \\
\text { população idosa e exposição a } \mathrm{MP}_{2,5} \text { em } \\
\text { decorrência das queimadas na Amazônia } \\
\text { brasileira em } 2005\end{array}$ \\
\hline $\begin{array}{l}\text { Rodrigues } \\
\text { et al. }\end{array}$ & $\begin{array}{l}\text { Regiões do } \\
\text { Estado de Ro }\end{array}$ & 2013 & $\begin{array}{l}\text { Distribuição espaço-temporal das } \\
\text { queimadas e internações por doenças } \\
\text { respiratórias em menores de cinco anos } \\
\text { de idade em Rondônia, } 2001 \text { a } 2010\end{array}$ \\
\hline Nardocci et al. & $\begin{array}{l}\text { Cubatão } \\
\text { (SP) }\end{array}$ & 2013 & $\begin{array}{l}\text { Poluição do ar e doenças respiratórias e } \\
\text { cardiovasculares: estudo de séries } \\
\text { temporais em Cubatão, São Paulo, Brasil }\end{array}$ \\
\hline $\begin{array}{l}\text { Nascimento } \\
\text { Francisco }\end{array}$ & $\begin{array}{l}\text { São José } \\
\text { Campos } \\
\text { (SP) }\end{array}$ & 2013 & $\begin{array}{l}\text { Material particulado e } \\
\text { hospitalar por hipertensação } \\
\text { uma cidade brasileira }\end{array}$ \\
\hline $\begin{array}{l}\text { Negrisoli } \\
\text { Nascimento }\end{array}$ & $\begin{array}{l}\text { Taubaté } \\
\text { (SP) }\end{array}$ & 2013 & $\begin{array}{l}\text { Poluentes atmosféricos e internações por } \\
\text { pneumonia em crianças }\end{array}$ \\
\hline Silva et al. & $\begin{array}{l}\text { Cuiabá } \\
\text { (MT) }\end{array}$ & 2013 & $\begin{array}{lll}\text { Material particulado originário } & \text { de } \\
\text { queimadas e doenças respiratórias } & \end{array}$ \\
\hline Smith et al. & $\begin{array}{l}\text { Acre } \\
(\mathrm{AC})\end{array}$ & 2014 & $\begin{array}{l}\text { A seca afeta a saúde respiratória das } \\
\text { crianças na Amazônia brasileira }\end{array}$ \\
\hline $\begin{array}{l}\text { Miraglia } \\
\text { Gouveia }\end{array}$ & $\begin{array}{l}\text { Regiões } \\
\text { Metropolitanas }\end{array}$ & 2014 & $\begin{array}{l}\text { Custos da poluição atmosférica nas } \\
\text { regiões metropolitanas brasileiras. }\end{array}$ \\
\hline Freitas et al. & $\begin{array}{l}\text { Capitais do } \\
\text { Brasil }\end{array}$ & 2014 & $\begin{array}{l}\text { Desastres naturais e saúde: uma análise } \\
\text { da situação do Brasil }\end{array}$ \\
\hline $\begin{array}{l}\text { Amâncio } \\
\text { Nascimento }\end{array}$ & $\begin{array}{l}\text { São José } \\
\text { Campos } \\
\text { (SP) }\end{array}$ & 2014 & $\begin{array}{l}\text { Poluição ambiental e óbitos devido a } \\
\text { acidente vasculoencefálico em uma cidade } \\
\text { com baixos níveis de poluentes: estudo } \\
\text { ecológico de séries temporais }\end{array}$ \\
\hline $\begin{array}{l}\text { Gavinier } \\
\text { Nascimento }\end{array}$ & $\begin{array}{l}\text { Sorocaba } \\
\text { (SP) }\end{array}$ & 2014 & $\begin{array}{l}\text { Poluentes atmosféricos e internações por } \\
\text { acidente vascular encefálico }\end{array}$ \\
\hline Artaxo & Brasil & 2014 & Mudanças climáticas e o Brasil \\
\hline
\end{tabular}




\begin{tabular}{|c|c|c|c|}
\hline Nicolussi et al. & $\begin{array}{l}\text { Ribeirão } \\
(\mathrm{SP})\end{array}$ & 2014 & $\begin{array}{l}\text { Poluição do ar e doenças respiratórias } \\
\text { alérgicas em escolares }\end{array}$ \\
\hline Pinheiro et al. & $\begin{array}{l}\text { São Paulo } \\
\text { (SP) }\end{array}$ & 2014 & $\begin{array}{l}\text { Efeitos isolados e sinérgicos do } \mathrm{MP}_{10} \text { e da } \\
\text { temperatura média na mortalidade por } \\
\text { doenças cardiovasculares e respiratórias }\end{array}$ \\
\hline Santos et al. & $\begin{array}{l}\text { São José dos } \\
\text { Campos } \\
\text { (SP) }\end{array}$ & 2014 & $\begin{array}{l}\text { O papel dos poluentes atmosféricos sobre } \\
\text { o peso ao nascer em cidade de médio } \\
\text { porte Paulista }\end{array}$ \\
\hline $\begin{array}{l}\text { Gonçalves } \\
\text { et al. }\end{array}$ & $\begin{array}{l}\text { Porto Velho } \\
\text { (RO) }\end{array}$ & 2014 & $\begin{array}{l}\text { Indicador de } \\
\text { socioambiental na Amazônia Ocidental. O } \\
\text { caso do município de Porto Velho, } \\
\text { Rondônia, Brasil }\end{array}$ \\
\hline Barbosa et al. & $\begin{array}{l}\text { São Paulo } \\
\text { (SP) }\end{array}$ & 2015 & $\begin{array}{l}\text { Poluição do ar e a saúde das crianças: a } \\
\text { doença falciforme }\end{array}$ \\
\hline Sathler et al. & $\begin{array}{l}\text { Amazônia } \\
\text { Legal }\end{array}$ & 2015 & $\begin{array}{l}\text { Mudanças climáticas e mitigação no setor } \\
\text { florestal: REDD+, políticas nacionais e } \\
\text { desenvolvimento sustentável local na } \\
\text { Amazônia }\end{array}$ \\
\hline César et al. & $\begin{array}{l}\text { Taubaté } \\
\text { (SP) }\end{array}$ & 2015 & $\begin{array}{l}\text { Material particulado fino estimado por } \\
\text { modelo matemático e internações por } \\
\text { pneumonia e asma em crianças }\end{array}$ \\
\hline $\begin{array}{l}\text { Barcellos } \\
\text { et al. }\end{array}$ & Brasil & 2016 & Um grau e meio. E daí? \\
\hline Moniz et al. & $\begin{array}{l}\text { Rio de Janeiro } \\
(R J)\end{array}$ & 2016 & $\begin{array}{l}\text { Percepção da qualidade ambiental de } \\
\text { localidades próximas ao Complexo } \\
\text { Petroquímico do Rio de Janeiro, Brasil }\end{array}$ \\
\hline Zanin et al. & $\begin{array}{l}\text { Biomas } \\
\text { Brasileiros }\end{array}$ & 2016 & $\begin{array}{l}\text { Mudanças climáticas e a cobertura vegetal } \\
\text { nativa: impactos em um país } \\
\text { megadiverso e seus biomas }\end{array}$ \\
\hline Cruz et al. & $\begin{array}{l}\text { São Carlos } \\
\text { (SP) }\end{array}$ & 2016 & $\begin{array}{l}\text { Internações hospitalares, óbitos, custos } \\
\text { com doenças respiratórias e sua relação } \\
\text { com alterações climáticas em São Carlos- } \\
\text { SP, Brasil }\end{array}$ \\
\hline Pereira et al. & $\begin{array}{l}\text { Porto Velho } \\
\text { (RO) }\end{array}$ & 2016 & $\begin{array}{l}\text { Análise de Condições Ambientais em } \\
\text { Comunidades Ribeirinhas de Porto Velho, } \\
\text { Rondônia, Brasil }\end{array}$ \\
\hline Silva et al. & $\begin{array}{l}\text { Rio Branco } \\
(\mathrm{AC})\end{array}$ & 2016 & $\begin{array}{l}\text { Alto risco de doenças respiratórias em } \\
\text { crianças no período de fogo na Amazônia } \\
\text { Ocidental }\end{array}$ \\
\hline $\begin{array}{l}\text { Nobre } \\
\text { Marengo }\end{array}$ & Brasil & 2017 & $\begin{array}{l}\text { Mudanças Climáticas em Rede: Um olhar } \\
\text { interdisciplinar }\end{array}$ \\
\hline Passos et al. & $\begin{array}{l}\text { Regiões do } \\
\text { Brasil }\end{array}$ & 2017 & $\begin{array}{l}\text { Doenças respiratórias agudas em crianças } \\
\text { brasileiras: os cuidadores são capazes de } \\
\text { detectar os primeiros sinais de alerta? }\end{array}$ \\
\hline Rodrigues et al. & $\begin{array}{l}\text { Cuiabá e Várzea } \\
\text { Grande (MT) }\end{array}$ & 2017 & $\begin{array}{l}\text { Variabilidade climática aumenta a } \\
\text { morbimortalidade associada ao material } \\
\text { particulado }\end{array}$ \\
\hline Moniz et al. & $\begin{array}{l}\text { Rio de Janeiro } \\
(R J)\end{array}$ & 2017 & $\begin{array}{l}\text { Diagnóstico participativo socioambiental e } \\
\text { de riscos à saúde das comunidades do } \\
\text { entorno do Complexo Petroquímico do Rio } \\
\text { de Janeiro, Brasil }\end{array}$ \\
\hline Souza et al. & $\begin{array}{l}\text { Campos dos } \\
\text { Goytacazes } \\
(\mathrm{RJ})\end{array}$ & 2017 & $\begin{array}{l}\text { Análise da distribuição espacial da área de } \\
\text { influência das queimadas de cana-de- } \\
\text { açúcar e prevalência dos sintomas de } \\
\text { asma em alunos do município de Campos } \\
\text { dos Goytacazes - RJ, no }\end{array}$ \\
\hline
\end{tabular}




\begin{tabular}{|llcl|l|}
\hline & & & período de 2012 e 2013 \\
\hline $\begin{array}{l}\text { Rodrigues } \\
\text { et al. }\end{array}$ & $\begin{array}{l}\text { Cuiabá e Várzea } \\
\text { Grande } \\
\text { (MT) }\end{array}$ & $\begin{array}{l}\text { Fatores de risco para mortalidade por } \\
\text { doenças cardiovasculares associados à } \\
\text { alta exposição ao tráfego veicular }\end{array}$ \\
\hline $\begin{array}{l}\text { Machin } \\
\text { Nascimento }\end{array}$ & $\begin{array}{l}\text { Cuiabá } \\
\text { (MT) }\end{array}$ & 2018 & $\begin{array}{l}\text { Efeitos da exposição a poluentes do ar na } \\
\text { saúde das crianças de Cuiabá }\end{array}$ \\
\hline $\begin{array}{l}\text { Municípios da } \\
\text { et al. }\end{array}$ & $\begin{array}{l}\text { Amazônia Legal } 2018 \\
\text { brasileira }\end{array}$ & $\begin{array}{l}\text { Desenvolvimento de modelos não lineares } \\
\text { prevendo concentrações diárias de } \\
\text { partículas finas usando a recuperação de } \\
\text { profundidade óptica de aerossóis e } \\
\text { medições terrestres em um município da } \\
\text { região amazônica brasileira }\end{array}$ \\
\hline
\end{tabular}

Figura 8 - Principais estudos que avaliaram os efeitos das mudanças climáticas e da poluição do ar na saúde humana no Brasil, com ênfase para grupos mais vulneráveis (2010-2018).

As discussões acerca das mudanças climáticas tiveram início em nível internacional a partir da Conferência das Nações Unidas sobre o Meio Ambiente Humano, realizada em junho de 1972 em Estocolmo. Nesse período, os governantes, as comunidades científicas e a população mundial desconheciam os riscos globais para a humanidade (HACON et al., 2010; RIBEIRO; PESQUEIRO, 2010; NOBRE; MARENGO, 2017).

A partir da criação do IPCC, em 1988, no âmbito das Nações Unidas (ONU), por iniciativa do Programa das Nações Unidas para o Meio Ambiente (PNUMA) e da Organização Meteorológica Mundial (OMM), os governantes, as sociedades científicas, as organizações não governamentais e uma pequena parcela da população mundial passaram a conhecer o tema, que foi internalizado pelas esferas governamentais nacionais e internacionais na Conferência das Nações Unidas sobre o Meio Ambiente e o Desenvolvimento, em junho de 1992, no Rio de Janeiro-RJ (IGNOTTI et al., 2010; JASINSKI et al., 2011; ZANIN et al., 2016). Ainda que o Painel Intergovernamental de Mudanças Climáticas tenha sido criado na década de 1980 , seus relatórios só passaram ao domínio da opinião pública após a divulgação pelas mídias de alguns de seus dados e cenários futuros quanto ao aumento dos Gases de Efeito Estufa (GEE) e ao aquecimento global, caso medidas não fossem tomadas pelos governos e pela sociedade. Segundo o Observatório do Clima (ODC, 2019), no Brasil foi possível alocar $95,7 \%$ das emissões de gases de efeito estufa aos Estados. A alocação foi feita para todo o período de 1970 a 2018. Neste último ano, os Estados do Pará $(12,3 \%$ do total) e Mato Grosso $(11,9 \%)$ aparecem como os principais emissores, seguidos de Minas Gerais (9,9\%), São Paulo $(8,7 \%)$ e Rio Grande do Sul $(6,6 \%)$. Enquanto a abordagem brasileira da mudança climática inicialmente focou na área de mitigação, medidas de adaptação foram integradas de forma incremental durante os últimos anos. Uma região focal desse novo debate é o semiárido nordestino do país, conhecido como sertão brasileiro. Possui uma extensão de $940 \mathrm{mil} \mathrm{km}^{2}$, abrange cerca de $86 \%$ da região do Nordeste geográfico. Chuvas irregulares, falta de acesso à água, longos períodos de estiagens e secas recorrentes afetam principalmente pobres agricultores familiares da região, tornando-a uma área de risco à mudança climática futura (PEREIRA et al., 2011; NUNES et al., 2013). 
Por outro ângulo, os cenários de mudanças climáticas para a Amazônia, projetados por modelos climáticos complexos e apresentados pelo IPCC, apontam para um aumento na temperatura média do ar bem acima de $4^{\circ} \mathrm{C}$ (até o final do século XXI) e redução nas chuvas de até 40\% (RODRIGUES et al., 2017; MACHIN; NASCIMENTO, 2018). Essa mudança na temperatura atmosférica tem potencial para gerar grandes desequilíbrios em ecossistemas vitais para a sobrevivência da humanidade. Segundo o Plano Nacional de Adaptação à Mudança do Clima, a América do Sul é o continente com maior risco de extinção de espécies nativas (23\%), maiormente em florestas tropicais.

As evidências de que a Amazônia já está vulnerável aos impactos das mudanças climáticas não podem ser relacionadas apenas aos efeitos do aumento na concentração de GEE na atmosfera, mas também a mudanças no uso da terra e à conversão de florestas pelo desmatamento (CRUZ et al., 2016). Desta forma, assim como algumas secas históricas foram associadas ao El Niño (1912, 1925, 1983, 1987, 1998), as secas mais recentes de 2005, 2010 e 2016 foram associadas a um oceano Atlântico Tropical Norte, e somente a seca de 2016 aconteceu num ano sob influência do El Niño. Isso é um exemplo de adicionalidade dos fatores externos ao clima local e regional (NASCIMENTO, 2012; CESAR et al., 2013; NOBRE, MARENGO, 2017).

A cada ano, aumenta-se o uso do fogo na Amazônia brasileira, principalmente em tempos de estiagem, em que a vegetação fica mais seca e o fogo se alastra com maior facilidade, de forma que qualquer faísca, dependendo da localidade, pode provocar uma verdadeira catástrofe (SANTOS et al., 2018; JESUS et al., 2020). Os incêndios florestais e o uso do fogo em sistemas agrícolas afetam o equilíbrio dos ecossistemas e a saúde humana (ALVINORAYOL et al., 2020). Este desequilíbrio, por sua vez, é influenciado pelo acelerado crescimento populacional, por mudanças no padrão de consumo e intensificação das atividades econômicas, capazes de exercer uma força motriz sobre o nível de qualidade de vida das populações expostas (SOUZA et al., 2017; RODRIGUES et al., 2017).

Apesar de anos de estudos científicos sobre os impactos dos poluentes atmosféricos em áreas urbanas e rurais e a atenção da mídia em relação ao desmatamento ilegal e aos incêndios florestais, acidentais ou intencionais, os potenciais efeitos à saúde das populações têm sido pouco estudados pela comunidade científica, principalmente em área dominadas por grandes fazendeiros, que inviabilizam a entrada de pesquisadores, criando um abismo entre a ciência e a saúde (GONÇALVES et al., 2012). As grandes queimadas em Bornéu (1983 e 1997), Tailândia (1997), Indonésia (1997), Roraima (1997 1998), Mato Grosso (1998) e Pará (1998) despertaram a atenção para o problema, mas as medidas tomadas para prevenir ou controlar os incêndios ainda são insuficientes (NOBRE, MARENGO, 2017; GONÇALVES et al., 2018).

Um dos grandes exemplos de perda florestal ocorreu durante o fenômeno do El Niño, em 1997 e 1998. O incêndio de Roraima queimou uma área entre 11.394 e $13.928 \mathrm{Km}^{2}$ de floresta primária intacta (FREITAS et al., 2014). Do ponto de vista legal, o Código Florestal Brasileiro, instituído pela Lei 4.771 de 15 de setembro de 1965, classifica como bens de interesse público as florestas e as demais formas de vegetação, devido à sua utilidade e às terras que revestem. Esta Lei limita o exercício dos direitos de propriedade sobre a utilização e exploração de florestas, sendo as ações ou omissões contrárias às disposições 
deste Código consideradas como uso nocivo da propriedade (YANAGI et al., 2012; BARROS et al., 2013, SATHLER et al., 2015).

Esses e outros episódios menos famosos foram suficientes para que se instituíssem medidas visando controlar os níveis ambientais de poluição do ar em diversos centros urbanos, sobretudo em países da América do Norte e Europa (GONÇALVES et al., 2014; ANDRADE FILHO et al., 2013). Fontes de poluentes, como a queima de combustíveis fósseis pelos motores, a combustão e a expansão das indústrias siderúrgicas ganharam força com a revolução industrial e isso ocorreu sem um acompanhamento dos possíveis danos que esses poluentes poderiam causar à saúde humana (BARBOSA et al., 2015; SILVA et al., 2016).

O Brasil passa por um momento de avanços na área médica, entretanto, carece de políticas públicas que proporcionem seguridade assistencial, causando grande desigualdade quanto às condições de assistência e disponibilidade de leitos para a população. Além das segregações socioeconômicas e a diferença na qualidade de vida dos brasileiros, o clima é um dos fatores contribuintes e agravantes na saúde humana (CARMO; GUIZARDI, 2018). Estudos como este refletem episódios em todas as grandes cidades do Brasil, que rotineiramente estão expostas a poluições excessivas, o que gerou um aumento no número de mortalidades, despertando interesse por estudos na área de Epidemiologia com a finalidade de analisar os efeitos dos poluentes atmosféricos na saúde, principalmente as concentrações de $\mathrm{MP}_{2.5}$ e $\mathrm{MP}_{10}$ em grupos mais vulneráveis (HACON et al., 2010; CARNESECA et al., 2012; CÉSAR et al., 2015; PASSOS et al., 2017; MACHIN; NASCIMENTO, 2018; GONÇALVES et al., 2018).

A Resolução 03/1990 do CONAMA, que visa definir os padrões de qualidade do ar em território brasileiro, foi considerada por muitos pesquisadores como "inconsistente", a despeito da disponibilização desses índices que se mostram deficientes, sobretudo em sua aplicação. Entretanto, o Conselho adotou novos padrões de medição de qualidade do ar que devem servir de parâmetro para o controle da poluição no país. A nova resolução, renomeada como "CONAMA no 491 de 19/11/2018", publicada em DOU em 21 de novembro de 2018, estabelece novos padrões de emissão e quantificação do material particulado fino, bem como outros poluentes. Essa afirmação encontra respaldo na medida em que se constatam inúmeros problemas relacionados com a poluição do ar: problemas respiratórios, cardíacos, poluição da areia e do mar através da emissão de pó de minério, emissão desenfreada de Dióxido de Carbono $\left(\mathrm{CO}_{2}\right)$ etc. Em resumo, a Resolução estabelece que o nível de partículas do tamanho de 10 micrômetros $\left(\mathrm{MP}_{10}\right)$ suspensas no ar não pode ultrapassar $120 \mathrm{\mu g} / \mathrm{m}^{3}$ em 24 horas. Já os materiais particulados de até 2,5 micrômetros de tamanho $\left(\mathrm{MP}_{2,5}\right)$ não podem ultrapassar os $60 \mu \mathrm{g} / \mathrm{m}^{3} \mathrm{em} 24$ horas (ALVES et al., 2020).

É importante salientar que, embora a Resolução estabeleça como prioridade atender metas estabelecidas pela OMS, não há nenhum tipo de instrumento de gestão ambiental em nível nacional ou estadual para que se cumpram estas metas. A cada ano, os Estados devem apresentar à União seus relatórios de qualidade do ar, necessário para não violação dos padrões de exposição das populações a diversos riscos de saúde. É preciso apresentar um mecanismo eficiente de gestão que possa instrumentalizar o setor 
governamental contra desequilíbrios e desmontes do meio ambiente (GONÇALVES et al., 2018).

Efeitos na morbidade também têm sido observados e incluem aumento em sintomas respiratórios em stakeholders mais vulneráveis, como crianças e idosos (IGNOTTI et al., 2010; CESAR et al., 2013; BARBOSA et al., 2015; BARCELLOS et al., 2016). No caso do Brasil, alguns estudos investigatórios dos efeitos da poluição do ar na saúde humana encontraram associações estatisticamente significativas com mortalidade infantil, mortalidade em idosos, além de hospitalizações em crianças e adultos por causas respiratórias (SANTOS et al., 2014; PINHEIRO et al., 2014; CRUZ et al., 2016; MACHIN; NASCIMENTO, 2018). Segundo a Organização Pan-Americana de Saúde no Brasil (OPAS), atualmente, $50 \%$ da população do planeta vive em cidades e aglomerados urbanos e está exposta a níveis progressivamente maiores de poluentes do ar, acima do legislado pelas agências de monitoramento (OPAS, 2016). A outra metade, majoritariamente nos países em desenvolvimento, utiliza combustíveis sólidos derivados de biomassa (madeira, carvão vegetal, esterco animal seco e outros) e combustíveis líquidos, em menor proporção, como fonte de energia para cocção, aquecimento e iluminação (SILVA et al., 2013; MIRAGLIA; GOUVEIA et al., 2014).

Rodrigues et al. (2013) alertam que estimativas de áreas queimadas ou fração de biomassa afetada pelo fogo são extremamente incertas, constituindo outra dificuldade importante para o cálculo da quantidade de material lançado na atmosfera. Esta modelagem é realizada através de um sistema computacional elaborado para simular e estudar o transporte atmosférico de produtos originários da queima de biomassa, utilizando parâmetros de difusão horizontais e verticais de radiação solar, umidade e temperatura, predizendo com boa precisão a concentração de alguns poluentes atmosféricos em regiões que exibem forte pressão sobre a atividade agrícola. Já para Farias et al. (2010), a comparação das estimativas do modelo CATT-BRAMS com medidas reais de $\mathrm{MP}_{2.5}$ aferidas in loco demonstrou um coeficiente de determinação de 0,7 , sendo bastante satisfatório por se tratar de estimativas de poluição a nível local (NARDOCI et al., 2013; BARROS et al., 2013; FREITAS et al., 2014; GONÇALVES et al., 2018).

À vista disso, a epistemologia ambiental, quando combinada de forma interdisciplinar e transversal, corrobora com uma visão macro politizada sobre as contribuições de autores e seu contexto no universo de uma pesquisa científica. Nos últimos oito anos, tem-se produzido um conjunto significativo de estudos na linha de ambiente e saúde, alterando os bancos de dados e constituindo um "estado do conhecimento" mais sólido e robusto, sobretudo com a participação de renomadas organizações e instituições mundiais (HACON et al., 2010; ARTAXO, 2014; NOBRE, MAREGO et al., 2017; MONIZ et al., 2017).

\section{CONCLUSÃO}

As mudanças climáticas têm sido o tema da ciência mundial na contemporaneidade. Estudos indicaram que essas mudanças sobre o clima podem ter impactos significativos, com diferenças entre as regiões do mundo. Tais impactos podem ressoar em diferentes setores: agrícola, saúde da 
população, biodiversidade dos ecossistemas, entre outros. Seus efeitos diretos na população englobam a exposição a condições extremas, como o estresse térmico das ondas de calor, e aos desastres naturais, entre secas e inundações e, por outro olhar, os efeitos indiretos estão mais associados às influências climáticas na proliferação de doenças disseminadas pelo ar, água e por alimentos (TORRES et al., 2020).

Todos os anos, milhões de pessoas são expostas aos perigos dos extremos de calor e ondas de calor, que podem ser letais. Em 2017, por exemplo, aconteceu um aumento de mais de 18 milhões de exposições a ondas de calor de pessoas vulneráveis em relação a 2016 (FLOSS; BARROS, 2019). A vulnerabilidade da população às ondas de calor é fortemente influenciada por ambientes sociais e físicos (GUO et al., 2018). Além disso, algumas regiões tropicais e subtropicais, como Brasil, Colômbia e Filipinas, são caracterizadas por um aquecimento esperado relativamente alto e alta mortalidade associada a ondas de calor (GASPARRINI et al., 2017; GUO et al., 2018Para os autores, é preciso considerar os efeitos frequentes dos episódios climáticos sobre a América do Sul, em especial, no Brasil, que é um dos países que vêm exibindo, nos últimos anos, aumento no número de dias com ondas de calor em seus diferentes estados, em decorrência do acréscimo de queimadas florestais e secas severas prolongadas, potencializando a dispersão de poluentes na atmosfera, agravando ainda mais a saúde humana, sobretudo dos grupos mais vulneráveis como crianças e idosos (ABREU et al., 2020). Projeções mostram que no futuro haverá o aumento da população idosa em áreas urbanas no Brasil, assim como o aumento da frequência e intensidade das ondas de calor devido às mudanças climáticas (SANDERSON et al., 2017).

Por outro lado, espera-se que todos os países europeus e os Estados Unidos experimentem um ligeiro aumento na mortalidade excessiva relacionada às ondas de calor (WANG et al., 2018). Em suma, a incerteza das mudanças climáticas e os pressupostos sobre adaptabilidade não são atribuídos à probabilidade, mas podem ser considerados como um futuro possível, dependendo da população, tecnologia, política de governança, desenvolvimento social e econômico (WATTS et al., 2018).

Todavia, a maioria dos artigos evidenciou associação entre os problemas de saúde (doenças respiratórias) e a poluição do ar, sobretudo em grupos mais suscetíveis, retratando a cultura do uso do fogo para a queima da biomassa morta devido ao desmatamento como a causa principal dessas alterações no ambiente. As frequências de publicações foram, maiormente, entre 2010 e 2012, mesmos anos em que foi constatado aumento exorbitante do desmatamento na Amazônia Legal e de casos de internações por doenças do aparelho respiratório. Dito isso, os estudos, em sua maioria, assimilaram que o aumento das concentrações de partículas de aerossóis de queimadas pode alterar substancialmente os padrões climáticos sobre o território brasileiro, ocasionando, assim, um aumento de casos de hospitalizações por doenças respiratórias. Em suma, esse cenário pode se agravar ainda mais na contemporaneidade devido à sobrecarga do Sistema Único de Saúde (SUS) com a SARS-CoV-2 (COVID-19). O quadro futuro dos efeitos das mudanças climáticas e da poluição do ar na saúde humana é um exercício humano necessário para uma nova releitura de mundo sobre a ciência da vida. 


\section{AGRADECIMENTOS}

Agradecemos à Coordenação de Aperfeiçoamento de Pessoal de Nível Superior (CAPES), pelo apoio financeiro via Bolsa de Pesquisa - Novo Programa de Formação Doutoral Docente - Portaria no 140, de 02 de outubro de 2013. À Universidade Federal Rural da Amazônia (UFRA), pelo apoio de infraestrutura, à Universidade do Estado de Mato Grosso Carlos Alberto Reys Maldonado (UNEMAT), pela disponibilidade no acesso interno das bases de dados (via CAFe) do portal de periódicos CAPES. Por fim, aos docentes do PPGCA - UNEMAT, pelas contribuições e ensinamentos durante a disciplina de Seminários Avançados.

\section{REFERÊNCIAS BIBLIOGRÁFICAS}

ABREU, A. M. et al. A interface entre saúde, mudanças climáticas e uso do solo no Brasil: uma análise da evolução da produção científica internacional entre 1990 e 2019. Saúde e Sociedade, v. 29, 2020. doi: 10.1590/S010412902020180866

ALCANTARA, L. C. S.; SAMPAIO, C. A. C. Bem Viver como paradigma de desenvolvimento: utopia ou alternativa possível? Desenvolvimento e Meio ambiente, Curitiba-PR, v. 40, 2017. doi: 10.5380/dma.v40i0.48566

ALENCAR, A.; et al. Amazônia em chamas 5: o que queima, e onde. Nota Técnica $n^{\circ}$ 5, IPAM - Instituto de Pesquisa Ambiental da Amazônia, agosto de 2020.

ALVES, L.; et al. Distribuição das concentrações de Ozônio $\left(\mathrm{O}_{3}\right)$ na área de influência do polo industrial de Camaçari-Bahia: prováveis impactos à Saúde Humana e ao Meio Ambiente. Revista Bras. Meio Ambiente, v. 8, n. 1, 2020.

ALVINO-RAYOL, F.; et al. Effect of fire in weeds of agroforestry system, Pará, Brazil. Revista de Ciências Agroveterinárias, v. 19, n. 1, p. 1-7, 2020.

AMÂNCIO, T. C.; NASCIMENTO, C. F. L. Asma e poluentes ambientais: um estudo de séries temporais. Revista da Associação Médica Brasileira, v.58, n.3, p.302-7, 2012. doi: 10.1590/s0104-42302012000300009

ANDRADE FILHO, V. S.; et al. Aerossóis de queimadas e doenças respiratórias em crianças, Manaus, Brasil. Revista de Saúde pública, São Paulo-SP, v. 47, n. 2, p. 239-247, 2013. doi: 10.1590/s0034-8910.2013047004011.

ANGELO, C.; RITTL, C. Análise das Emissões de Gases de Efeito Estufa e suas implicações para as metas do Brasil. Observatório do Clima, 2019.

ARBEX, M. A.; et al. A poluição do ar e o sistema respiratório. Jornal Brasileiro de Pneumologia, São Paulo, v.38, n.5, p.643-655, 2012.

ARTAXO, P. Mudanças climáticas e o Brasil. Revista USP, n. 103, p. 8-12, 2014.

BARBOSA, S.; et al. Poluição do ar e a saúde das crianças: a doença falciforme. Cadernos de Saúde Pública, Rio de Janeiro-RJ, v.31, n.2, p.265-75. 2015.

BARCELLOS, C.; et al. Mudanças climáticas e ambientais e as doenças infecciosas: cenários e incertezas para o Brasil. Epidemiologia e Serviços de Saúde, v.18, n. 3, p. 285-304, 2009. doi: 10.5123/S167949742009000300011. 
BARCELLOS, C.; et al. Um grau e meio. E daí?. Cadernos de Saúde Pública, São Paulo-SP, v. 32, p. 1-3, 2016. doi: 10.1590/0102-311x00212315

BARROS, M. M.; et al. Reinternações hospitalares por doenças respiratórias em menores de 12 anos e as queimadas em Porto Velho-RO, Interfacehs-Revista de Saúde, Meio Ambiente e Sustentabilidade, São Paulo-SP, v. 8, n. 3, 2013.

BUENO, N. F.; et al. Perfil epidemiológico de internações por pneumonia em crianças no Tocantins entre 2014 e 2018. Revista de patologia do Tocantins, v. 7, n. 3, p. 3-6, 2020.

BRADFORD, S. C. Sources of information on specific subjects. Engineering, v. 137, p. 85-86, 1934. doi: 10.1177/016555158501000406

BRASIL - Conselho Nacional do Meio Ambiente (CONAMA). Resolução no 491, de 19 de novembro de 2018 - Novos padrões nacionais de qualidade do ar. Programa Nacional de Controle da Qualidade do Ar - PRONAR, 2018.

CARMO, C. N. D.; et al. Associação entre material particulado de queimadas e doenças respiratórias na região sul da Amazônia brasileira. Revista Panamericana de Salud Pública, São Paulo-SP, v. 27, p. 10-16, 2010.

CARMO, M. E.; GUIZARDI, F. L. O conceito de vulnerabilidade e seus sentidos para as políticas públicas de saúde e assistência social. Cadernos de Saúde Pública, v. 34, p. e00101417, 2018. doi: 10.1590/0102-311X00101417

CARNESECA, E. C.; et al. Associação entre a poluição atmosférica por material particulado e contagens mensais de procedimentos de inalação e nebulização em Ribeirão Preto, São Paulo, Brasil. Cadernos de Saúde Pública, São Paulo-SP, v. 28, p. $1591-1598$, 2012. doi: 10.1590/s0102-311x2012000800017

CESAR, G. C. A.; et al. Associação entre exposição ao material particulado e internações por doenças respiratórias em crianças. Revista de Saúde Pública, São Paulo-SP, v.47, n.6, 2013. doi: 10.1590/S0034-8910.2013047004713

CÉSAR, A. C. G.; et al. Material particulado fino estimado por modelo matemático e internações por pneumonia e asma em crianças. Revista Paulista de Pediatria, v. 34, n. 1, p. 18-23, 2015. doi: 10.1016/j.rppede.2015.12.005

CORRÊA, A. V. S.; et al. Relação entre queimadas e casos de doenças respiratórias em crianças e idosos na época da seca no Tocantins. Revista de Patologia do Tocantins, v. 7, n. 3, p. 75-79, 2020.

CRUZ, D.; et al. Internações hospitalares, óbitos, custos com doenças respiratórias e sua relação com alterações climáticas no município de São Carlos - SP, Brasil. Medicina (Ribeirão Preto Online), v. 07, n. 3, 2016.

DASTOORPOOR, M.; et al. Air pollution and hospital admissions for cardiovascular diseases in Ahvaz, Iran. Science of the Total Environment, v. 652, p. 1318-1330, 2019. doi: 10.1016/j.scitotenv.2018.10.285

DUARTE, T. R. O painel brasileiro de mudanças climáticas na interface entre ciência e políticas públicas: identidades, geopolítica e concepções epistemológicas. Sociologias, v. 21, n. 51, p. 76-101, 2019. 
ECHEGARAY, F.; AFONSO, M. H. F. Respostas às mudanças climáticas: inovação tecnológica ou mudança de comportamento individual? Estudos Avançados, v. 28, n. 82, p. 155-174, 2014. doi: 10.1590/S0103-40142014000300010

FARIAS, M. C.; et al. Prevalência de asma em escolares de Alta Floresta município ao Sudoeste da Amazônia brasileira. Revista Brasileira de Epidemiologia, São Paulo-SP, v. 13, p. 49-57, 2010.

FERNANDES, T.; et al. Air pollution and effects on the health of children in the Amazon region of para: a bibliometric Analysis. Research, Society and Development, v. 8, n. 4, p. 4984907, 2019. doi: 10.33448/rsd-v8i4.907

FERNANDES, T.; et al. Dinâmica temporal de focos de calor e seus condutores de pressão no território do Sudeste Paraense. Revista Nativa - Agrárias e Ambientais, Sinop-MT, v. 7, n. 6, p. 681-692, 2019. doi: 10.31413/nativa.v7i6.7909

FERNANDES, T.; et al. Variabilidade das chuvas e sua relação com os Objetivos de Desenvolvimento Sustentável em populações expostas a mudanças hídricas no sudeste da Amazônia paraense. Revista Brasileira de Geografia Física, v. 13, n. 04, p. 1519-1536, 2020. doi: 10.26848/rbgf.v13.4.p1519-1536

FONSECA-MORELLO, T.; et al. Queimadas e incêndios florestais na Amazônia brasileira: porque as políticas públicas têm efeito-limitado. Ambiente \& Sociedade, São Paulo, v. 20, n. 4, p. 19-40, 2017.

FLEURY, L. C.; et al. Mudanças climáticas, ciência e sociedade. Sociologias, v. 21 , n. 51 , p. $18-42$, 2019. doi: 10.1590/15174522-0215101

FLOSS, M.; BARROS, E. F. Saúde planetária: conclamação para a ação dos médicos de família de todo o mundo. Revista Brasileira de Medicina de Família e Comunidade, v. 14, n. 41, p. 1992-1992, 2019.

FREITAS, C. M. D.; et al. Desastres naturais e saúde: uma análise da situação do Brasil. Ciência \& Saúde Coletiva, Rio de Janeiro-RJ, v. 19, p. 3645-3656, 2014.

GASPARRINI A.; et al. Projeções de excesso de mortalidade relacionado à temperatura em cenários de mudanças climáticas. Lancet Planet Health, 1 (9): e360 - e7, 2017.

GONÇALVES, K.; et al. As queimadas na região amazônica e o adoecimento respiratório. Ciência \& Saúde Coletiva, Rio de Janeiro-RJ, v. 17, n. 6, 2012.

GONÇALVES, K. S.; et al. Desenvolvimento de modelos não lineares que preveem concentrações diárias de partículas finas usando recuperações ópticas de aerossóis e medições baseadas no solo em um município da região amazônica brasileira. Atmospheric Environment, v. 184, p. 156-165, 2018.

GONÇALVES, K. S.; et al. Indicador de vulnerabilidade socioambiental na Amazônia Ocidental. O caso do município de Porto Velho, Rondônia, Brasil. Ciência \& Saúde Coletiva, Rio de Janeiro-RJ, v. 19, p. 3809-3818, 2014.

GUO, Y.; et al. Quantificando o excesso de mortes relacionadas a ondas de calor em cenários de mudanças climáticas: Um estudo de modelagem de série temporal em vários países. Medicina PLoS , v. 15, n. 7, pág. e1002629, 2018. 
HACON, S. S.; et al. Vulnerabilidade, riscos e impactos das mudanças climáticas sobre a saúde do Brasil. Em Terceira Comunicação Nacional sobre Mudanças Climáticas à UNFCC. TCN-UNFCC. 2010.

HARTWIG, S. V.; IGNOTTI, E. Variações meteorológicas e as alterações de pressão arterial dos pacientes em hemodiálise: revisão sistemática. Revista Brasileira de Climatologia, Curitiba-PR, v. 25, 2019.

IGNOTTI, E.; et al. Poluição do ar e admissões hospitalares por doenças respiratórias na Amazônia subequatorial: abordagem de séries temporais. Cadernos de Saúde Pública, v. 26, n. 4, p. 747-61, 2010.

IPCC - Intergovernamental Panel on Climate Change. The Science of Climate Chang. - The Scientific Basis - Contribution of Working Group 1 to the IPCC. The Assessment Report, Cambridge University, 2015.

JASINSKI, R.; et al. Poluição atmosférica e internações hospitalares por doenças respiratórias em crianças e adolescentes em Cubatão, São Paulo, Brasil, entre 1997 e 2004. Cadernos de Saúde Pública, Rio de Janeiro-RJ, v.27, n.11, p.224252, 2011. doi: 10.1590/s0102-311×2011001100017

JESUS, J. B.; et al. Análise da incidência temporal, espacial e de tendência de fogo nos biomas e unidades de conservação do Brasil. Ciência Florestal, v. 30, n. 1, p. 176-191, 2020. doi: 10.5902/1980509837696

MACHIN, A. B.; NASCIMENTO, L. F. C. Efeitos da exposição a poluentes do ar na saúde das crianças de Cuiabá, Mato Grosso, Brasil. Cadernos de Saúde Pública, Rio de Janeiro-RJ, v. 34, p. e00006617, 2018.

MEIMEI, X.; et al. Spatiotemporal analysis of particulate air pollution and ischemic heart disease mortality in Beijing, China. Environmental Health. v. 13, n.109, p. 1-12, 2014.

MENEZES, R. A. M.; et al. Exposição a poluentes do ar e doença respiratória em meninos e meninas. Revista Paulista de Pediatria, v. 37, n. 2, p. 166-172, 2019. doi: 10.1590/1984-0462/;2019;37;2;00009

MIRAGLIA, S. G. K.; GOUVEIA, N. Custos da poluição atmosférica nas regiões metropolitanas brasileiras. Ciência \& Saúde Coletiva, Rio de Janeiro-RJ, v. 19, p. 4141-4147, 2014. doi: 10.1590/1413-812320141910.09232014.

MONIZ, M. D. A.; et al. Diagnóstico participativo socioambiental e de riscos à saúde das comunidades do entorno do Complexo Petroquímico do Rio de Janeiro, Brasil. Ciência \& Saúde Coletiva, Rio de Janeiro-RJ, v. 22, p. 37933806, 2017.

MORAES, S. L.; et al. Variáveis meteorológicas e poluição do ar e sua associação com internações respiratórias em crianças: estudo de caso em São Paulo, Brasil. Cadernos de Saúde Pública, v. 35, p. e00101418, 2019.

NASCIMENTO, L. F. C. Poluentes ambientais e internações devido a acidente vasculoencéfalico. Cadernos de Saúde Pública, Rio de Janeiro-RJ, v.28, n.7, p.1319-24, 2012. doi: 10.1590/s0102-311x2012000700010.

NARDOCCI, A. C.; et al. Poluição do ar e doenças respiratórias e cardiovasculares: estudo de séries temporais em Cubatão, São Paulo, Brasil. Cadernos de Saúde Pública, Rio de Janeiro, v.29, v.9, p.1867-76, 2013. 
NOBRE, C. A.; MARENGO, J. A. Mudanças Climáticas em Rede: Um olhar interdisciplinar. Contribuições do Instituto Nacional de Ciência e Tecnologia para Mudanças Climáticas. 1a edição, Bauru, SP. 2017.

NUNES, K. V.; et al. Mortalidade por doenças circulatórias na população idosa e exposição a $\mathrm{MP}_{2,5}$ em decorrência das queimadas na Amazônia brasileira em 2005. Cadernos de Saúde Pública, Rio de Janeiro-RJ, v. 29, p. 589-598. 2013.

ODC - Observatório do Clima. Panorama Geral das emissões brasileiras Síntese 2017 / 2018. Análises das Emissões de Gases de Efeito Estufa no Brasil. 2019

OMS - Organização Mundial de Saúde. Mudança climática e saúde humana riscos e respostas: resumo atualizado 2008, Brasilia-DF: OPAS/OMS, 2008, 37p.

OPAS - Organização Pan-Americana de Saúde. Níveis de poluição do ar estão crescendo em muitas das cidades mais pobres do mundo. Desastres Naturais e Saúde no Brasil. Ministério da Saúde, Brasília, DF, 2016. Disponível em: https://www.paho.org/bra/index.php?option=com_content\&view=category\&layo ut=blog\&id $=845 \&$ Itemid $=839$ Acesso em: 12 set. 2020 .

PASSOS, S. D.; et al. Doenças respiratórias agudas em crianças brasileiras: os cuidadores são capazes de detectar os primeiros sinais de alerta? Revista Paulista de Pediatria, São Paulo-SP, v. 36, n. 1, p. 3-9, 2017.

PEREIRA, V. S.; et al. Análise dos atendimentos ambulatoriais por doenças respiratórias no Município de Alta Floresta-Mato Grosso-Amazônia brasileira. Epidemiologia e Serviços de Saúde, v. 20, n. 3, p. 393-400, 2011.

PEREIRA, C. A. R.; et al. Análise de condições ambientais em comunidades ribeirinhas de Porto Velho, Rondônia, Brasil. Revista Brasileira de Geografia Física, Recife-PE, v. 9, p. 440-455, 2016. doi: 10.26848/rbgf.v9.2.p440-455

PINHEIRO, S. L. L.; et al. Efeitos isolados e sinérgicos do $\mathrm{MP}_{10}$ e da temperatura média na mortalidade por doenças cardiovasculares e respiratórias. Revista de Saúde Pública, São Paulo-SP, v.48, n.6, p.881-8, 2014.

RÉQUIA, W. J.; ABREU, L. Monteiro. Poluição atmosférica e a saúde de crianças e idosos no Distrito Federal no período de 2007 a 2009: utilização do método de correlação com time delay. Revista Brasileira de Geografia Médica e da SaúdeHygeia, v. 7, n. 13, p. 95-108, 2011.

RIBEIRO, H.; PESQUERO, C. Queimadas de cana-de-açúcar: avaliação de efeitos na qualidade do ar e na saúde respiratória de crianças. Estudos Avançados, v. 24, n. 68, p. 255-271, 2010. doi: 10.1590/s0103-40142010000100018

RIGOTTO, R. M.; AUGUSTO, L.G.S. Saúde e ambiente no Brasil: desenvolvimento, território e iniquidade social. Cadernos de Saúde Pública, v. 23, p. 475-485, 2007.

RODRIGUES, P. C. O.; et al. Distribuição espaço-temporal das queimadas e internações por doenças respiratórias em menores de cinco anos de idade em Rondônia, 2001 a 2010. Epidemiologia e Serviços de Saúde, Brasília-DF, v. 22, n. 3, p. 455-464, 2013. doi: 10.1590/1413-81232017221.09622015

RODRIGUES, P. C. O.; et al. Fatores de risco para mortalidade por doenças cardiovasculares associados à alta exposição ao tráfego veicular. Revista Brasileira de Epidemiologia, São Paulo-SP, v. 20, p. 423-434, 2017. 
RODRIGUES, P. C. O.; et al. Variabilidade climática aumenta a morbimortalidade associada ao material particulado. Revista de Saúde Pública, São Paulo-SP, v. 51, p. 91, 2017. doi: 10.11606/s1518-8787.2017051006952

ROSA, A. M.; et al. Doença respiratória e sazonalidade climática em menores de 15 anos em um município da Amazônia brasileira. Jornal de Pediatria, v. 84, n. 6, p. 543-549, 2008.

RUIZ, M. A.; et al. Fator de impacto: importância e influência no meio editorial, acadêmico e científico. Revista Brasileira de Cirurgia Cardiovascular, São PauloSP, v. 24, n. 3, p. 273-278, 2009. doi: 10.1590/s0102-76382009000400004

SANDERSON, M.; et al. The use of climate information to estimate future mortality from high ambient temperature: A systematic literature review. PLoS One. 7;12(7):e0180369, 2017. doi: 10.1371/journal.pone.0180369

SANTOS, V.; et al. O papel dos poluentes atmosféricos sobre o peso ao nascer em cidade de médio porte Paulista. Revista Paulista de Pediatria, São Paulo-SP, v. 32, n. 4, p. 306-312, 2014. doi: 10.1016/j.rpped.2014.06.003

SANTOS, J.; et al. Fogo na agricultura: medidas preventivas e queima controlada no projeto de desenvolvimento sustentável Terra Nossa, Novo Progresso, Pará. Revista Agroecossistemas, v. 10, n. 2, p. 353-366, 2018. doi: 10.18542/ragros.v10i2.5211

SATHLER, D.; et al. Mudanças climáticas e mitigação no setor florestal: REDD+, políticas nacionais e desenvolvimento sustentável local na Amazônia Legal. Revista Brasileira de Estudos de População, Rio de Janeiro-RJ, v. 32, n. 3, p. $619-630$, 2015. doi: 10.1590/s0102-30982015000000038

SILVA, C. M. A.; et al. Material particulado originário de queimadas e doenças respiratórias. Revista de Saúde Pública, São Paulo, v.47, n.2, p.345-52, 2013.

SILVA, P. R. S.; et al. Alto risco de doenças respiratórias em crianças no período de fogo na Amazônia. Revista de Saúde Pública, São Paulo-SP, v. 50, p. 1, 2016.

SOUZA, A.; et al. Poluição atmosférica urbana a partir de dados de aerossóis MODIS: Efeito dos parâmetros meteorológicos. Boletim Goiano de Geografia, Goiana-GO, v. 37, n. 3, p. 466-483, 2017. doi: 10.5216/bgg.v37i3.50766

TORRES, P. H. C.; et al. Nem leigos nem peritos: o semeador e as mudanças climáticas no Brasil. Política \& Sociedade, v. 19, n. 44, p. 17-38, 2020.

VENTURA, D.; et al. Desafios da pandemia de COVID-19: por uma agenda brasileira de pesquisa em saúde global e sustentabilidade. Cadernos de Saúde Pública, v. 36, p. e00040620, 2020. doi: 10.1590/0102-311X00040620

TORRES, L. M.; et al. Poluição atmosférica em cidades brasileiras: uma breve revisão dos impactos na saúde pública e meio ambiente. Naturae, v. 2, n. 1, p. 23-33, 2020.

WANG, Y.; et al. Accounting for adaptation and intensity in projecting heat wave-related mortality. Enviro Res, 464-471, 2018. doi: 10.1016/j.envres.2017.11.049 
WATTS N.; et al. The 2018 report of the Lancet Countdown on health and climate change: shaping the health of nations for centuries to come. Lancet 392(10163):2479-514, 2018. doi: 10.1016/S0140-6736(18)32594-7

YANAGI, Y.; et al. Influência do material particulado atmosférico na incidência e mortalidade por câncer no Município de São Paulo, Brasil. Cadernos de Saúde Pública, Rio de Janeiro, v.28, n.9, p.1737-48, 2012.

YAP, J.; et al. Particulate air pollution on cardiovascular mortality in the tropics: impact on the elderly. Environmental Health, v. 18, n. 1, 2019. doi: 10.1186/s12940-019-0476-4

ZANIN, M.; et al. Mudanças climáticas e a cobertura vegetal nativa: impactos em um país megadiverso e seus biomas. Modelagem climática e vulnerabilidades setoriais à mudança do clima no Brasil. Ministério da Ciência, Tecnologia, Inovação e Comunicação, Brasília-DF, p. 93-125, 2016 